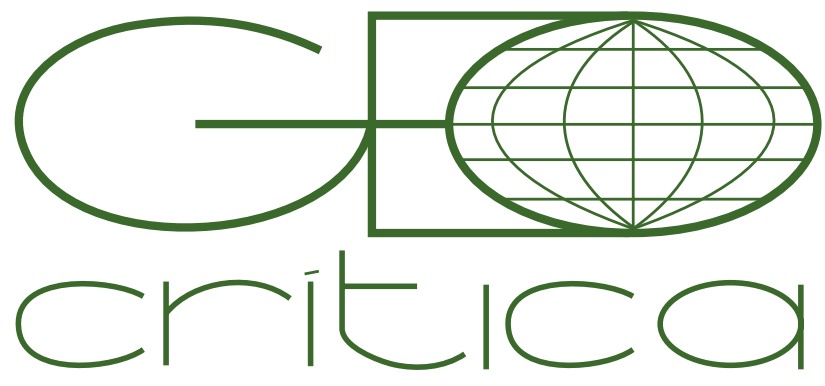

\section{Scripta Nova}

Revista Electrónica de Geografía y Ciencias Sociales Universitat de Barcelona

15 de diciembre de 2017

\title{
AIRBNB EN MENORCA: ¿UNA NUEVA FORMA DE GENTRIFICACIÓN TURÍSTICA?: LOCALIZACIÓN DE LA VIVIENDA TURÍSTICA, AGENTES E IMPACTOS SOBRE EL ALQUILER RESIDENCIAL
}

Este artículo ha sido financiado por la beca Wallanders W16-0455. Se ha recibido financiación adicional a partir de una beca de investigación del Institut Menorquí d'Estudis (convocatoria 2016) y del proyecto "Crisis y reestructuración de los espacios turísticos del litoral español" (CSO2015-64468-P), financiado por el Ministerio de Economía y Competitividad. Quiero agradecer la ayuda y trabajo dedicado de Paula Bibiloni en la recopilación de datos referentes al alquiler residencial, así como la ayuda de Jorge Lorenzo, Ivan Murray y John Östh en la producción cartográfica. Así mismo, los comentarios de los revisores han ayudado a mejorar la versión final del artículo.
Ismael Yrigoy

<ismael.yrigoy@kultgeog.uu.se>
Recibido: 17 de abril de 2017. Devuelto para correcciones: 24 de julio de 2017. Aceptado: 23 de septiembre de 2017.
Airbnb en Menorca: ¿una nueva forma de gentrificación turística? Localización de la vivienda turística, agentes e impactos sobre el alquiler residencial (Resumen)

Este artículo estudia si la irrupción de Airbnb en Menorca supone una nueva tipología de gentrificación turística. El objetivo es analizar desde una perspectiva geográfica y social el fenómeno de los alquileres turísticos en dicha isla. Se cartografía la distribución de las viviendas turísticas ofertadas en Airbnb y se realiza un análisis de la tipología de huéspedes que alquilan sus viviendas. Se estudia también el impacto de la vivienda turística sobre el mercado de vivienda residencial. La principal conclusión es que, en las zonas urbanas menorquinas, la irrupción de Airbnb ha creado los mecanismos para provocar un proceso de gentrificación a corto plazo.

Palabras clave: Airbnb, alquiler residencial, alquiler turístico, gentrificación turística, Menorca.

\section{Airbnb in Menorca: a new form of touristic gentrification? Distribution} of touristic housing dwelling, agents and impacts on the residential rent (Abstract)

This article studies if the irruption of Airbnb in Minorca is leading towards a new type of tourism gentrification. The objective is to analyze from a geographical and social perspective the phenomenon of tourism in Minorca. The distribution of touristic housing dwellings offered in Airbnb is mapped; and an analysis of the type of hosts is carried out. The impact of the touristic rentals on the residential rental market is also studied. The main finding is that, in the Minorca urban settlements, Airbnb irruption has created the mechanisms to trigger gentrification in the short-run.

Keywords: Airbnb, residential rental, tourist rental, tourism gentrification, Minorca. 
Uno de los fenómenos territoriales que están causando mayor disparidad de opiniones sobre sus efectos es la irrupción del alquiler vacacional, y concretamente, del portal de Airbnb. En el caso menorquín, han aparecido titulares de prensa con epígrafes tales como "alquiler vacacional, un ingreso extraordinario" ${ }^{1}$; "los propietarios que alquilan su vivienda turísticamente explican que es un complemento a sus ingresos y también una ayuda para poder mantener su patrimonio familiar" ${ }^{2} \mathrm{O}$ "los propietarios de vivienda (...) han encontrado en esta modalidad de negocio una manera de salir de la crisis tras la pérdida de su trabajo"3 . El presente artículo pretende por un lado matizar este creciente relato triunfalista del alquiler turístico y por otro, explorar las relaciones entre la irrupción del alquiler vacacional y el mercado de alquiler residencial en la isla. Siguiendo el reciente trabajo de Agustín Cócola ${ }^{4}$, en que se afirma que Airbnb supone un nuevo hito en los procesos de gentrificación turística, este trabajo analiza hasta qué punto la llegada de Airbnb supone la irrupción de una nueva oleada de gentrificación turística. El objetivo principal del artículo es analizar la irrupción del fenómeno de los alquileres turísticos ofertados por Airbnb en la Isla de Menorca desde una doble óptica espacial y social.

La aproximación a este fenómeno se estudia a partir de tres aspectos interrelacionados. En primer lugar, la dimensión geográfica del mismo: dónde se ubican espacialmente las viviendas turísticas ofertadas por Airbnb. La pregunta que se responde es, ¿en qué zonas de la isla se ubican estas viviendas? En segundo lugar, y a nivel social, se analizan las tipologías principales de huéspedes que alquilan viviendas mediante Airbnb. ¿Son particulares y familias humildes cómo afirma la propia Airbnb? ¿O son por el contrario grandes empresarios inmobiliarios cómo afirman movimientos sociales de Barcelona, Palma o Eivissa? En tercer lugar, se pretenden analizar los impactos que la irrupción de Airbnb puede tener sobre el mercado local de la vivienda. La cuestión central aquí es saber cómo está afectando la irrupción de Airbnb los precios del mercado de alquiler. Estas cuestiones son del máximo interés social, pero sin embargo, apenas existen trabajos académicos que estudien estas cuestiones 5 .

La hipótesis de partida es que el portal Airbnb ofrece un nuevo canal de comercialización para viviendas que ya tenían previamente un uso turístico en Menorca, pero a la vez y sobretodo, la irrupción de dicho portal ha provocado es la incorporación de nuevas plazas turísticas en la Isla. En segundo lugar, otra hipótesis es que la mayor parte de las viviendas están concentradas geográficamente en Maó y Ciutadella. Además, se presupone de partida que los precios de alquiler residencial han aumentado considerablemente como consecuencia de la proliferación de la vivienda con fines de alquiler turístico. Se presupone también que ha habido un trasvase

\footnotetext{
1 Ginard, 28/10/2016

2 Galán, 12/04/2017

3 Galán, 12/04/2017

4 Cócola,2016

5 Para excepciones, véase Arias y Quagleri, 2016; Cócola, 2016
} 
del parque de viviendas del alquiler residencial hacia el alquiler turístico, lo cual se ha traducido en una carencia relativamente grave de vivienda para residentes.

El artículo se estructura de la siguiente forma. El primer apartado discute las aportaciones teóricas y empíricas relacionadas con el concepto de gentrificación turística y su utilidad para el caso de estudio que nos ocupa. El segundo apartado repasa las principales fuentes y metodologías usadas en el trabajo. El siguiente epígrafe contextualiza la presente burbuja de Airbnb en Menorca dentro de la historia de la historia del turismo menorquín. El cuarto apartado se centra en explicar cuantitativamente la expansión espacial de las viviendas ofertadas por Airbnb a lo largo de la geografía menorquina. La quinta sección estudia la tipología de agentes que alquilan viviendas en la isla, mientras que el sexto apartado analiza los impactos que la proliferación de vivienda vacacional tiene sobre el mercado del alquiler residencial. La séptima sección esboza las conclusiones principales del trabajo.

\section{El papel del turismo en las dinámicas de gentrificación: Las nuevas líneas de fuga abiertas por Airbnb}

En su acepción inicial, Neil Smith ${ }^{6}$ definió gentrificación como un proceso de sustitución social de estratos sociales humildes por otros con mayor poder adquisitivo. Desde entonces, el término gentrificación ha sido usado para explicar múltiples procesos, hasta el punto de convertirse en un "concepto caótico"7 con una falta de "especificidad teórica y empírica"8

Dentro de estas múltiples ramificaciones del concepto de gentrificación, una particularmente relevante para este estudio es la de gentrificación turística, término acuñado por Kevin Fox Gotham, quien concibe este concepto para "resaltar el rol que la política pública tiene en promover tanto la gentrificación y el desarrollo turístico; y las acciones de grandes compañías de ocio (...) en remodelar [los lugares] en espacios de entretenimiento y consumo" ${ }^{\prime \prime}$. Siguiendo la línea marcada por Gotham, existen trabajos que explícitamente han responsabilizado al turismo de procesos de gentrificación en diversas ciudades españolas como Bilbao ${ }^{10}$; Palma de Mallorca $^{11}$, Santa Cruz de Tenerife ${ }^{12}$ o Valencia ${ }^{13}$. En todas estos casos se ubica temporalmente el proceso gentrificador en algún punto de la efervescencia de la burbuja inmobiliaria de 1995-2007. De acuerdo con estos trabajos, la administración pública en Valencia, Palma, Bilbao o Santa Cruz fue quien, mediante megaproyectos o megaeventos creó una oferta turística que indujo a las dinámicas gentrificadoras

\footnotetext{
6 Smith, 1979

7 Lees, 2003:2491

8 Gotham, 2005:1102.

9 Gotham, 2005: 1100

10 Vicario y Martínez, 2003; 2005

11 Morell, 2009; Vives-Miró, 2011

12 García et al, 2007

13 Romero y Trudelle, 2011
} 
provocando un aumento de los procesos de compraventa de vivienda y un desplazamiento y sustitución social.

No obstante, tal y como el caso de Barcelona ${ }^{14}$, la irrupción de Airbnb supone una nueva frontera para los procesos de gentrificación turística en tanto que consta de unas características peculiares que no estaban presentes en etapas previas de gentrificación. De esta forma, cada tipo de gentrificación tiene "unas características peculiares inscritas en un proceso común"15. Sin duda, el "proceso común" entre la gentrificación turística de la burbuja inmobiliaria española y la actual Airbnbificación existe y es el mismo: subida de precios de la vivienda y consiguiente proceso de desplazamiento social. Existen sin embargo, unas "características peculiares" de esta particular oleada de gentrificación turística que aquí se define como Airbnbficación.

En primer lugar y a diferencia de la anterior etapa de gentrificación, el ataque sobre el régimen de alquiler no viene vía una trasmutación de la vivienda de alquiler hacia el mercado de la compraventa, sino en un cambio en el propio concepto del alquiler. Así, si en los procesos de gentrificación de las décadas de los ochenta, noventa y dos mil estaban basados en un calentamiento del mercado de la compraventa mediante la renovación de edificios deteriorados y su posterior venta, la Airbnbficación actúa, al menos en un primer momento, sobre el mercado del alquiler. El alquiler ya no es un arrendamiento de base mensual para residentes, sino que va cada vez más ligado al arrendamiento de base diaria, y no para residentes, sino para turistas.

Así, por gentrificación turística se entiende aquí el proceso mediante el cual el mercado de viviendas de alquiler se reduce en favor de un mercado de viviendas de alquiler turístico, con la consiguiente dificultad potencial de acceso a la vivienda por parte del residente que no vaya al mercado de la compraventa o herede una vivienda. Además, existen otros puntos novedosos en la actual gentrificación turística. Contrariamente a la gentrificación previa al 2007, el elemento catalizador del actual proceso gentrificador no es la realización de megaeventos o megaproyectos urbanísticos impulsados por la colaboración público-privada sino la disrupción digital marcada por la aparición de nuevos canales de comercialización en la web o en apps. Si la administración pública jugó un papel clave en el impulso de estos megaproyectos, su actual papel ante los cambios que impulsa Airbnb es más bien reactivo, cuando no pasivo.

Por último, no cabe olvidar que las dinámicas de gentrificación turística que aquí se describen están enraizadas en la interacción de dos sectores económicos clave en Menorca: turismo y mercado inmobiliario. A partir de los años setenta, el sol y playa se abrió paso en la isla hasta erigirse en el baluarte de la economía menorquina y de la mano del turismo hubo un espectacular auge del mercado inmobiliario, y especialmente, de las segundas residencias. No en vano, el turismo en el conjunto

14 Cócola, 2016

15 Wyly y Hammel, 1998:332 
del archipiélago balear representa en la actualidad el $44.8 \%$ del PIB y el $32 \%$ de la fuerza de trabajo se emplea en dicho sector ${ }^{16}$.

En tanto que el turismo necesita de bienes inmuebles, éste se convierte en un factor dinamizador del mercado de la vivienda y repercute en sus precios. Tanto desde un punto de vista teórico como de caso de estudio, el turismo residencial aquel que usa como alojamiento la vivienda- es el nexo de unión entre las esferas de turismo, vivienda, y mercado inmobiliario. Sin embargo, la aparición de Airbnb desarrolla nuevos aspectos en dicha asociación turismo-mercado inmobiliario en tanto que la interacción monetaria en vivienda producida por el turismo no es mayoritariamente en forma de compraventa (como en el caso del turismo residencial tradicional de segundas residencias) sino en forma de alquiler; y geográficamente, esta interacción tiene lugar no sólo en zonas litorales y rurales, sino también y sobre todo en zonas urbanas. En este contexto de una potenciación del uso de la vivienda como alojamiento turístico gracias a Airbnb, se hace imperiosa la necesidad de saber en Menorca quién está llevando a cabo este proceso, su impacto sobre el mercado de alquiler residencial así como su difusión geográfica.

¿Qué es Airbnb y cuál es su historia? Airbnb es una página web que tiene como objetivo poner en contacto a personas que alquilan una casa o habitación por unos días con personas que desean visitar un destino turístico sin pernoctar en las acomodaciones turísticas al uso. La semilla para la creación de Airbnb se plantó en 2007, cuando tres estudiantes de San Francisco pusieron tres colchones en su piso de estudiantes y los alquilaron por internet ${ }^{17}$. La intención de los estudiantes era atraer a aquellos visitantes que no querían pagar los altos precios de los hoteles de la ciudad. Viendo esta oportunidad de negocios, estos estudiantes crearon su propia página web en 2008, que en 2009 se convirtió a la actual página web Airbnb.com. En esta página ya no sólo se alquilaban habitaciones, sino también viviendas enteros, así como - de una forma minoritaria- balcones, sofás, tiendas de campaña, barcos y cualquier medio que pueda ser usado para realizar una pernoctación. El impacto de la página web fue inmediato y global. La web se fundó en 2009, y en Menorca, los primeros anuncios se remontan a 2010. Con más de dos millones de anuncios, 640.000 huéspedes y una valoración de mercado de 25 millones de dólares en 2016, Airbnb se considera uno de los ejemplos más exitosos de la denominada economía colaborativa $^{18}$.

\section{Metodología y fuentes}

La principal fuente que se ha usado en este trabajo han sido datos cuantitativos. En un trabajo basado eminentemente en información cuantitativa como el presente, la dificultad más habitual radica en el propio proceso de obtención de datos. Este artículo no es una excepción.

16 Exceltur y Govern de les Illes Balears, 2015

17 Guttentag ,2015: 1192-1193

18 Martin, 2016 
Una primera dificultad que se ha afrontado ha sido la de poder obtener datos fiables en cuanto al número de viviendas turísticas. Históricamente, no ha existido este tipo de información en las fuentes de datos oficiales. Así, a nivel histórico, la estimación que se ha considerado más fiable es la de viviendas vacantes de los censos del Instituto Nacional de Estadística. El INE divide su contabilidad de las viviendas, al menos desde el año 1981, entre los siguientes parámetros: viviendas principales, secundarias, y viviendas vacías. Las viviendas vacías son aquellas que están disponibles para venta o alquiler, o simplemente están abandonadas ${ }^{19}$. Así pues, la obtención de datos sobre viviendas con potencial uso turístico se ha realizado a partir de estimaciones indirectas usando los censos del INE. Similarmente, una segunda dificultad añadida ha sido la de obtención de datos sobre la vivienda turística en la actualidad. Una primera fuente usada en este sentido ha sido el Consejo Insular de Menorca, que ha facilitado los datos relativos a viviendas turísticas regladas. Por otra parte, se han obtenido datos sobre las viviendas turísticas ofertados en Airbnb, que casi en la totalidad de los casos son viviendas no regularizados. La fuente usada para obtener los datos sobre Airbnb han sido obtenidos a partir de "webscrapping" de la propia web de Airbnb.com en marzo de 2017. Adicionalmente, información adicional ha sido obtenida a partir de la página web de insideairbnb.com, que ofrece bases de datos de la isla de Menorca para los meses de marzo de 2016 y noviembre de 2016. La naturaleza de los métodos de obtención de información hace que los datos obtenidos deban tratarse con cautela, puestos que los datos obtenidos son de los anuncios que estaban online en un momento determinado. Así, aquellos anuncios de viviendas que estaban ocupadas o que van a ser ofertadas en temporada alta no pueden ser obtenidos mediante las técnicas usadas en éste trabajo.

Una vez obtenidos esta masa de información alfanumérica, la representación en mapas se ha llevado mediante las herramientas de análisis espacial del programa ArcGIS. A partir de los modelos de densidad que ofrece el programa, se han llevado mapas de densidad de plazas turísticas residenciales por kilómetro cuadrado. En este sentido, el cálculo de densidades espaciales es el más adecuado para representar la difusión espacial de un fenómeno ya que "dan más peso a los puntos localizados al centro que a los que están ubicados más lejos" ${ }^{20}$. El resto de datos numéricos se han tratado con Microsoft Excel.

Una tercera dificultad ha sido la falta de datos oficiales referidos a los precios de alquiler. Las estadísticas del Ministerio de Fomento y del Instituto Nacional de Estadística recogen datos sobre los precios de compraventa, pero no de alquiler. Por otra parte, los portales inmobiliarios ofrecen información sobre los precios actuales del alquiler, pero no sobre la evolución histórica de estos precios. Así, la evolución histórica de los precios de alquiler de vivienda de Menorca ha sido obtenida mediante los anuncios clasificados de la hemeroteca de Es Diari de Menorca.

19 INE, 2011

20 Pons et al, 2015:243 
Aparte de esta fuente cuantitativa de información primaria, se han usado otras fuentes de información secundaria, principalmente noticias de prensa local, estatal e internacional sobre una variedad de cuestiones relacionadas con los temas del presente estudio.

\section{Contextualización histórica de los alojamientos turísticos en Menorca} Si el despegue turístico en Mallorca e Ibiza se empezó a producir a principios de los cincuenta, en Menorca éste se producirá a finales de los años sesenta. Así, , en 1965 las Islas Baleares recibieron un millón de turistas, con un reparto geográfico desigual. Mallorca recibió el 89\% de los turistas; Ibiza un 9,4\%, Menorca un 1.3\% y Formentera un $0,3 \%^{21}$. En este sentido, hay un amplio consenso en la historiografía en señalar un "retraso" del desarrollo turístico menorquín respecto al resto de las Islas Baleares ${ }^{22}$. En 1964, Menorca contaba con 1.893 plazas hoteleras, representando el $2.23 \%$ de capacidad de alojamiento turístico de las Islas Baleares. En todo caso, las plazas hoteleras menorquinas se multiplicarán por seis en el período 1964-73, pasando de 1.893 plazas a 11.721 ; logrando una consolidación en el período 1974-80 (de 11.721 plazas a 12.656) (figura 1).

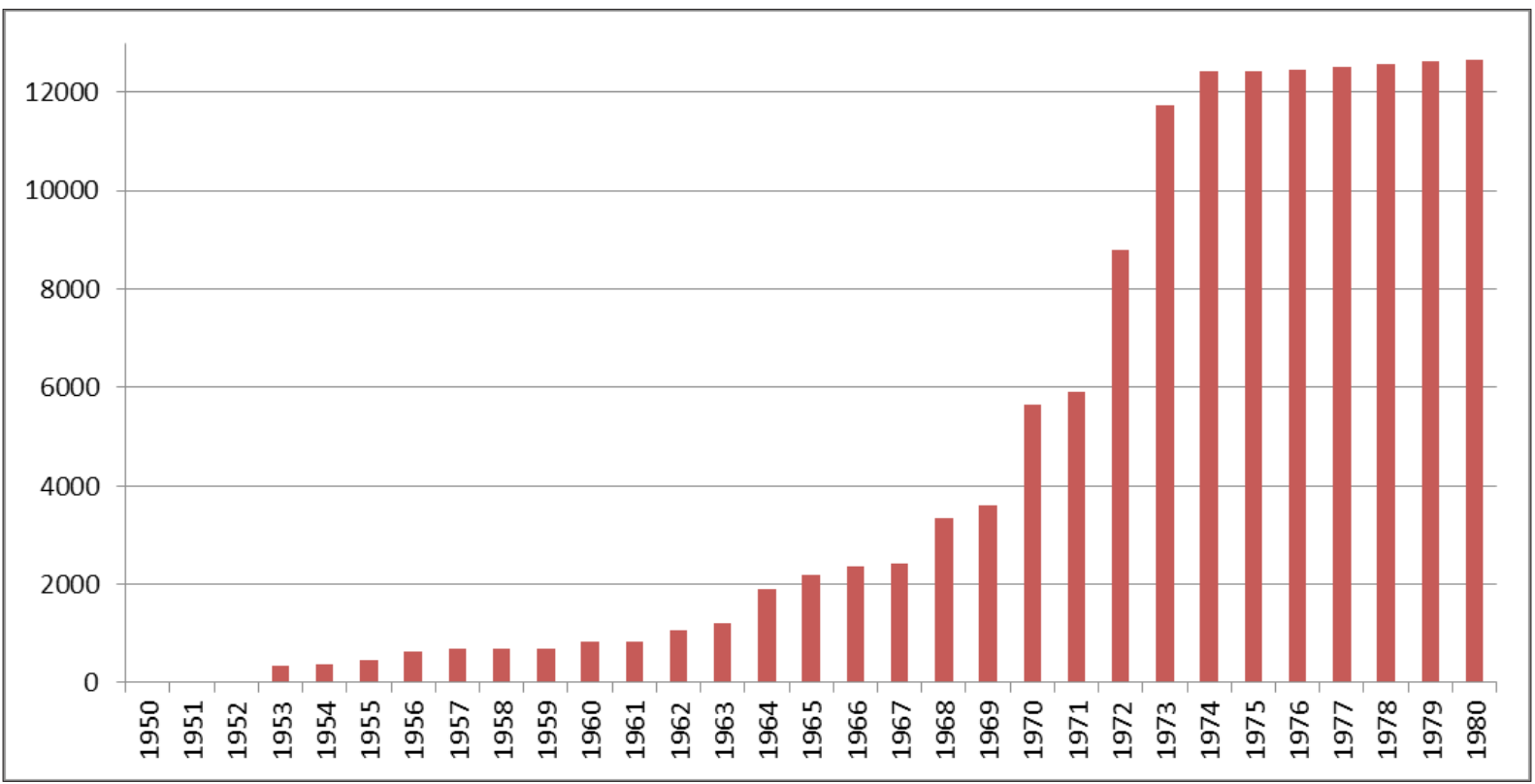

Figura 1. Plazas hoteleras en Menorca entre 1950 y 1980.

Fuente: elaboración propia a partir de Conselleria de Turisme, 2015.

Un elemento clave para el despegue del turismo en Menorca fue la construcción de un aeropuerto adecuado para los vuelos a reacción en 1969. De hecho, fue gracias a la inauguración del nuevo aeropuerto cuando se pudo producir un empuje en la especialización turística de Menorca: “de los 13.000 pasajeros extranjeros registrados en 1968 nos encontraremos con casi 57.000 en 1970. Y sólo cinco años más tarde se registrarán unos 158.000 visitantes"23.

21 Martínez de la Cruz y Utrilla Navarro, 1999: 60-61

22 Casasnovas, 2006

23 Martínez de la Cruz y Utrilla Navarro, 1999: 68 
Tal y como pasó en el resto de espacios turísticos mediterráneos litorales españoles, de la mano del desarrollo hotelero tuvo lugar un proceso de urbanización turística residencial. De esta forma, "las urbanizaciones propiamente dichas comenzarán a partir de los años 1968-69, es decir, cuando el turismo ya es un negocio claro en Menorca (...). Respecto a la forma de usufructo, encontramos una gran variedad de formas y combinaciones: la urbanización de propietarios que disfrutan la modalidad de alquiler (...); el que combina el chalet de compra y el apartamento de alquiler del que se hace cargo la empresa urbanizadora; el grupo solo de apartamentos que se da muy raramente; $y$, finalmente, la urbanización ligada a un hotel que, aparte, se puede combinar con alguna de las modalidades anteriores (compra, alquiler) “24. Así mismo, las plazas turísticas residenciales que éxitos a finales de los setenta eran del orden de 8.750, casi la mitad del total de las plazas hoteleras ${ }^{25}$.

Según los datos del Instituto Nacional de Estadística, las cifras de viviendas no principales aumentaron desde 942 en 1960 hasta 4.480 en 1970. Si en 1960, el 7,69\% de las viviendas en Menorca no eran principales, esta cifra aumentó hasta el 24.9\% en 1970. Las zonas donde se registraron mayores incrementos en el número de viviendas en la isla fueron en Ciutadella, en Es Castell, pero sobretodo en Sant Lluís, donde proliferaron una ingente cantidad de urbanizaciones turísticas. Además, a medida que el parque de viviendas aumentaba en Menorca, mayor parte de ellas estaban destinadas a usos no principales (por tanto, total o parcialmente recreativas). En una fecha tan temprana como 1970, casi un cuarto del parque total de las viviendas menorquinas no tenían un uso principal, una cifra muy considerable pero inferior a Mallorca (donde un $28 \%$ de viviendas eran no principales) e Ibiza (donde un $32 \%$ de las viviendas eran no principales).

El crecimiento urbano y turístico en este periodo tuvo la cobertura legal de los planes urbanos municipales, amparado por las sucesivas leyes estatales del suelo de 1956 y $1975^{26}$. En el caso menorquín estos planes dieron como resultado la ampliación los núcleos tradicionales menorquines de viviendas unifamiliares en medianera mediante ensanches bloques de pisos en altura, especialmente en Maó y Ciutadella, y por otro lado, la realización de urbanizaciones turísticas en zonas litorales vía plan parcial27. Por otro lado, otras urbanizaciones turísticas que difícilmente hubieran sido llevadas a cabo en el marco de la Ley del Suelo de 1956 sí que lo fueron al abrigo de la Ley de Zonas y centros turísticos de 1963 -casos de Cala Turqueta en Ciutadella o Son Parc, Platges de Fornells y Tirant en Es Mercadal ${ }^{28}$. Con estos instrumentos de planeamiento se consolidó un modelo urbanizador en que la construcción de vivienda en entornos litorales tuvo ciertamente una vocación turístico-recreativa.

24 Farré-Escofet et al,1977:239

25 Ferré-Escofet et al, 1977: 240

26 Cortès Marqués, 1990; Murray, 2006

27 Domènec et al, 1983

28 Ripoll, 1990: 74 
Si se considera esta masa de viviendas no principales como potenciales plazas residenciales turísticas y se comparan con las plazas hoteleras se observa que estas plazas residenciales en el conjunto de la isla prácticamente cuadruplicaban el total de plazas hoteleras (figura 2). Además, se observan unas diferencias considerables entre Maó y Ciutadella: mientras que en Ciutadella las plazas residenciales potenciales eran menores a las plazas hoteleras, en Maó se invertían las tornas, multiplicando las plazas residenciales potenciales por tres a las plazas hoteleras (figura 2).

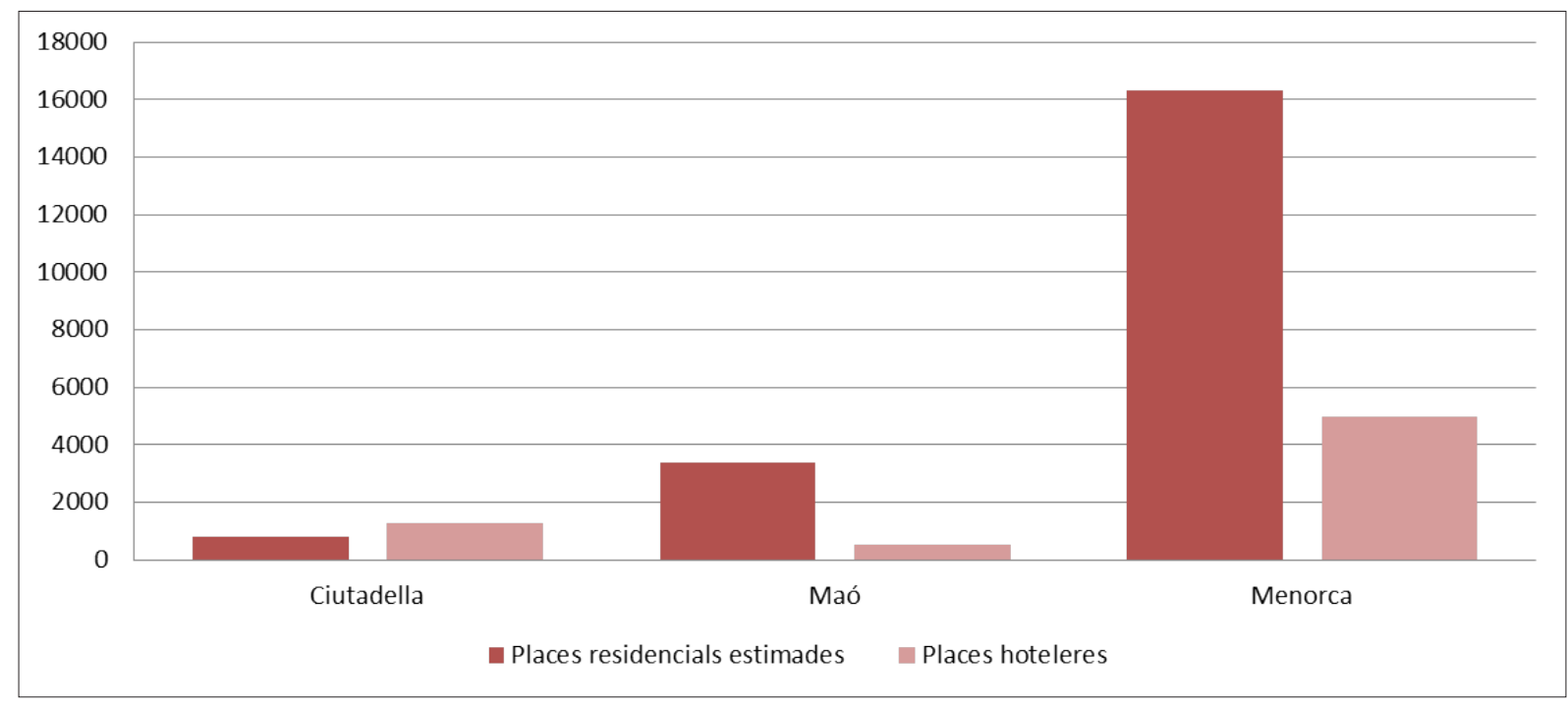

Figura 2. Plazas Hoteleras y estimación de plazas turísticas residenciales potenciales en Menorca, año 1970

Fuente: Elaboración propia a partir de Conselleria de Turisme, 2015, e INE, 1971.

Desde 1984 en adelante y sobre todo a finales de los noventa dará un nuevo período de crecimiento el ámbito del turismo y del alojamiento turístico en Menorca, con una continuación del crecimiento de plazas tanto hoteleras como extra-hoteleras $^{29}$. Respecto a las plazas hoteleras, éstas prácticamente se cuadriplican: de las 4.960 plazas de 1970 se pasa a 18.894 plazas en 1991. El incremento es aún más espectacular en apartamentos turísticos: de las 371 plazas en toda Menorca a apartamentos en 1970 se pasó a 20.234 en $1991^{30}$. Dentro de este contexto de incremento, las plazas residenciales potenciales serán las que tendrán un aumento residencial menor: de las 16.630 plazas potenciales en viviendas vacantes en 1970 se pasarán a 23.603 plazas en 1991 (figura 3).

De cualquier modo, hay que resaltar que la proporción entre plazas turísticas hoteleras y no hoteleras pasará a estar claramente decantada a favor de las últimas -incluso sin considerar las potenciales plazas residenciales no reguladas-. Así, la suma de plazas en apartamentos turísticos y/o en viviendas turísticas sobrepasaban las plazas hoteleras en el año 1991 (figura 3).

Por municipios, cabe destacar como entre 1988 y 1994, la capacidad de alojamiento turístico de Ciutadella (mayor municipio turístico de Menorca), se incre-

29 Cortès Marqués, 1990

30 Conselleria de Turisme, 2015 
mentó en un 128\%, hasta alcanzar unas 16.952 plazas en 1994, convirtiéndose en el municipio de Baleares con mayor proporción de plazas en apartamento turísticos, con el $66,05 \%$ del total. Alaior se convirtió en el segundo municipio turístico de la isla y fue el que experimentó el mayor incremento de plazas de alojamiento turístico $(144,54 \%)$ de la isla. Las plazas de alojamiento turístico se incrementaron a todos los demás municipios menorquines, excepto en Es Castell con una disminución del $10,16 \%{ }^{31}$. Para el periodo 1994-2001, Menorca fue nuevamente la isla balear donde hubo un mayor incremento de las plazas turísticas. Estas aumentaron un 15,48\% entre 1994 y 2001.

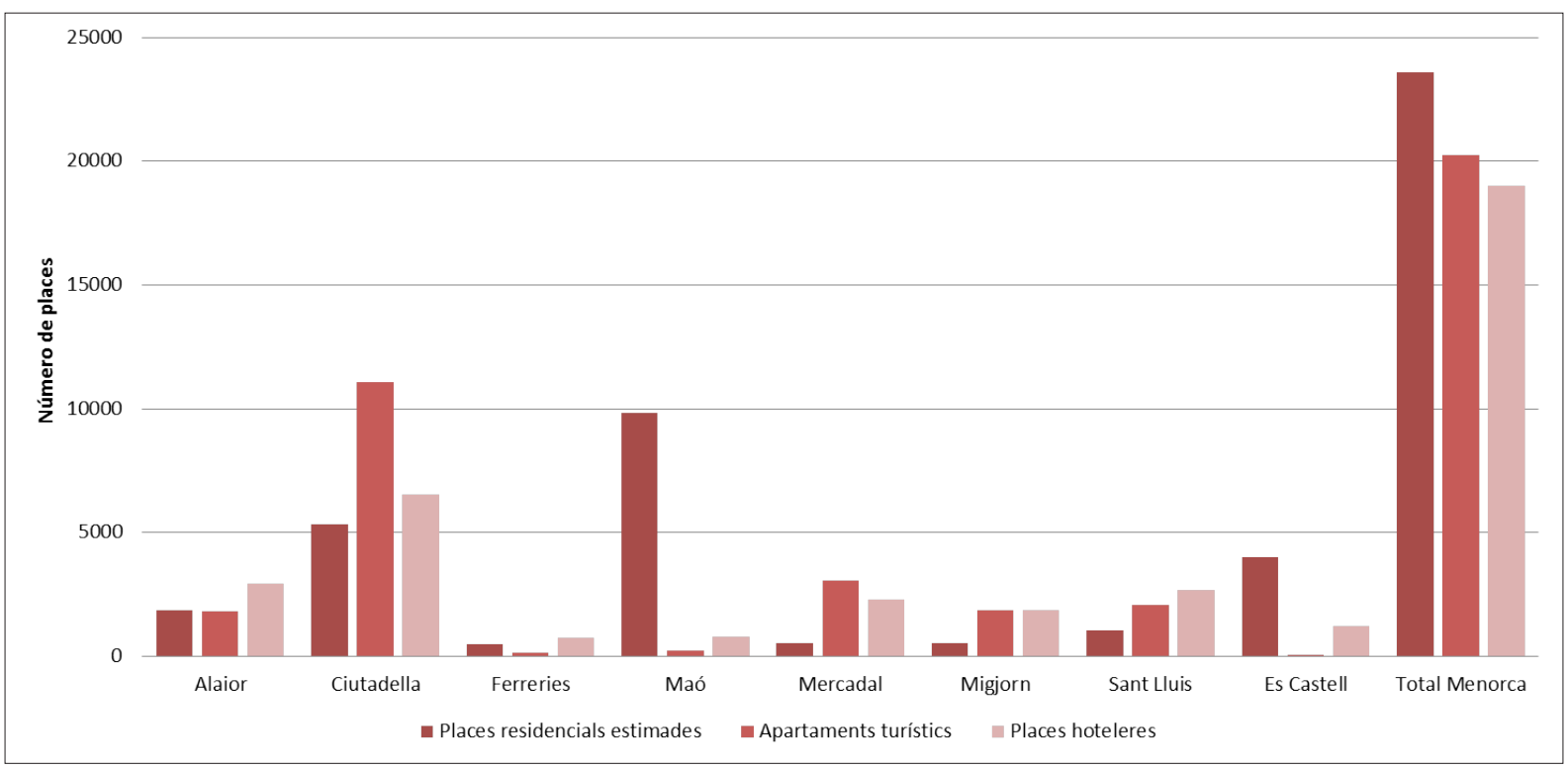

Figura 3. Plazas hoteleras, en apartamentos y estimación de plazas turísticas residenciales potenciales en Menorca, año 1991

Fuente: elaboración propia a partir de Conselleria de Turisme, 2015 e INE, 1991.

La década de los dos mil supuso una aceleración de los ritmos de construcción de edificación residencial destinadas sobre todo a la compraventa, aunque también se produjo una importante ralentización del incremento de nuevas plazas en hoteles y apartamentos turísticos, en el marco de un planeamiento insular que perseguía ralentizar el crecimiento. En efecto, la entrada en vigor de la Ley autonómica de Ordenación Territorial en 1987 dio como resultado la aprobación de las Directrices de Ordenación Territorial en 1999, directrices que debían desarrollarse en cada isla mediante un plan territorial redactado por cada Consejo Insular. Así, en 2003 se aprobaría el Plan Territorial Insular de Menorca, que focalizó el crecimiento entorno a los núcleos ya existentes -tanto tradicionales como turísticos- prohibiendo el crecimiento en zonas rurales, entre otras medidas de contención del crecimiento ${ }^{32}$.

En la actualidad, el parque de viviendas en Menorca tiene un patrón marcadamente dual, con la existencia por un lado de núcleos tradicionales con un parque de viviendas mayoritariamente plurifamiliares o unifamiliares con medianera y por

31 Murray, 2012: 1850

32 Consell Insular de Menorca, 2005 
otro lado, nuevas urbanizaciones litorales en su mayoría de corte suburbano y de vocación eminentemente turística que han ido proliferando en el litoral desde los años sesenta.

Más allá de la cuestión del crecimiento urbanístico, la planificación sectorial turística balear no reguló el uso turístico de la vivienda hasta la aprobación de la Ley General del Turismo de 2012, en que se permitió la vivienda vacacional en edificios unifamiliares aislados o aparejados -comunes en las urbanizaciones litorales y de los cascos históricos-, pero no en plurifamiliares - más habituales en los ensanches de los núcleos tradicionales-. Sin embargo y cómo se verá a continuación, la llegada de plataformas en línea de alquiler de vivienda como Airbnb ha supuesto la proliferación de usos turísticos de la vivienda en tipologías edificatorias no previstas en la ley turística.

\section{Las viviendas turísticas vacacionales ofrecidas en Airbnb y su distribución espacial}

Tal y cómo se ha afirmado en el apartado anterior, la vivienda turística vacacional ha existido en Menorca prácticamente desde los inicios del desarrollismo turístico (véanse figuras 2-4). Así, el Consell Insular de Menorca dispone de una base de datos sobre plazas residenciales reguladas ${ }^{33}$ que arroja datos elocuentes: de las 4 plazas turísticas en viviendas en 1979 (cuando había 12.656 plazas hoteleras) se pasaron a 20.363 plazas turísticas en viviendas en 2016 (cuando había 29.772 plazas hoteleras $)^{34}$. En los últimos cuarenta años las plazas legales en viviendas turísticas se han multiplicado por 5090; mientras que en el mismo periodo, las plazas en apartamentos turísticos se han multiplicado por 18,79 y las plazas hoteleras se han multiplicado por 2,35 (véase figura 4). Las zonas con mayor densidad de plazas residenciales regladas son la costa del municipio de Ciutadella desde Cala Picas hasta Cala Santandria (ambos núcleos incluidos), además de las zonas de Cala en Bosc y Cala Morell. En el municipio de Ferreries destaca Cala Galdana; en Es Mercadal la zona de Arenal d'en Castell; y el conglomerado de urbanizaciones de Punta Grossa-Coves Noves- Urbanización Macaret y Port d’Addaia. En el este destacan toda la zona del Puerto de Maó (incluidos Es Castell, Maó y Cala Llonga). En Sant Lluís las zonas con mayor densidad de plazas son el propio núcleo de Sant Lluís, Punta Prima, Binibéquer y Binisafúller . En todo caso, el mayor número de plazas turísticas regladas están situadas en centro histórico de Ciutadella, en Cala Galdana y en Binibéquer.

A día de hoy en Menorca, cada una de las tres tipologías de alojamiento turístico (hoteles, apartamentos turísticos y viviendas turísticas) representa grosso modo un tercio de las plazas turísticas del total. En 2016, las plazas hoteleras eran 29.772; las plazas en apartamentos 23.366, y las plazas residenciales reguladas eran 20.362. No obstante, si se añaden las viviendas turísticas vacacionales alquiladas en el portal de

33 Por plazas/viviendas residenciales regladas o viviendas turísticas vacacionales se entienden sólo las viviendas que en algún momento del año se dedican al alquiler a turistas, no a las viviendas que tienen un uso exclusivo como segunda residencia y/o que son propiedad de extranjeros.

34 Consell Insular de Menorca , 2017 
Airbnb $^{35}$ a las viviendas reguladas, se obtienen un total de 32.233 plazas turísticas residenciales para 2016, superiores a las plazas hoteleras y a las plazas en apartamentos (figura 4).

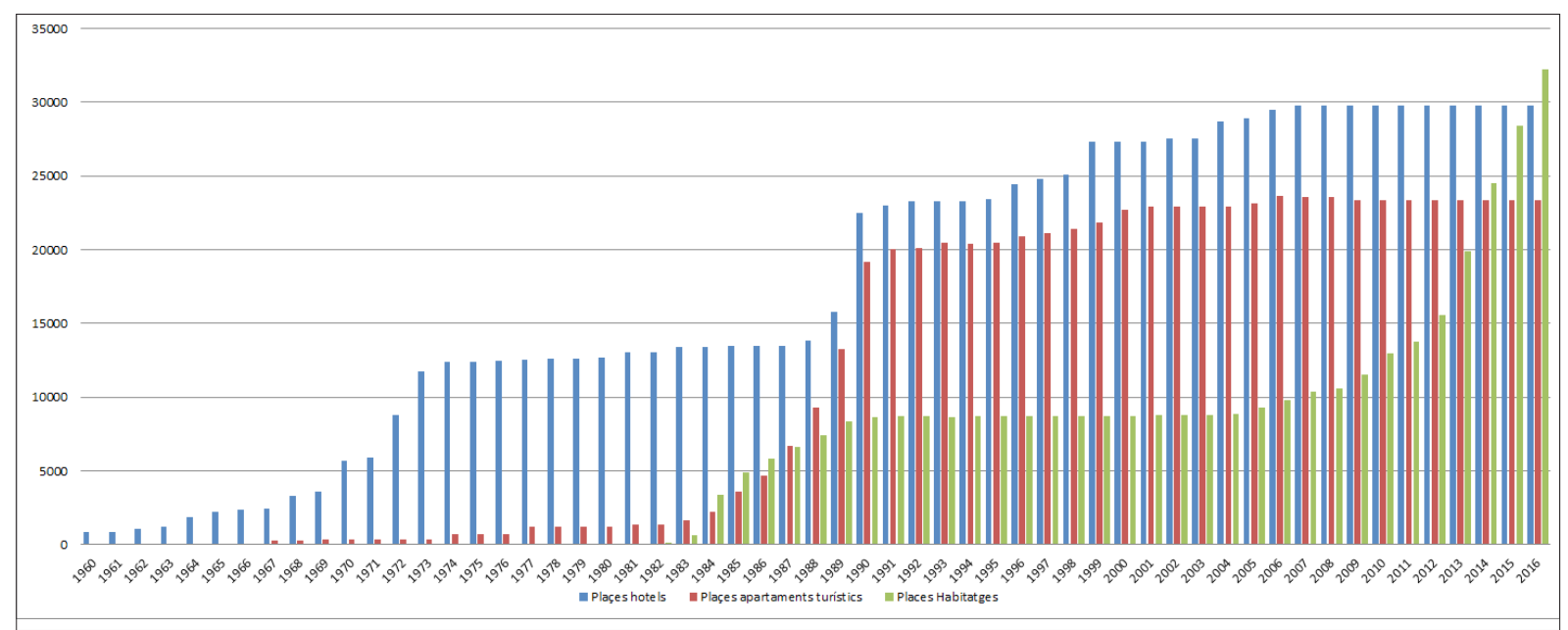

Figura 4: Evolución de plazas hoteleras, plazas en apartamentos y plazas residenciales (regladas y no regladas) en Menorca (1960-2016).

Fuente: elaboración propia a partir de Conselleria de Turisme (2015) y Consell Insular de Menorca (2017).

En efecto, a principios de 2017 había en Menorca 16.327 plazas turísticas residenciales no reguladas disponibles en Airbnb distribuidas en 2.401 viviendas. Esta cifra es inferior a otros puntos calientes del alquiler vacacional en España - el municipio de Eivissa tenía 4.111 viviendas alquiladas en Airbnb a finales de 2016; el municipio de Palma 2.969; el distrito centro de Madrid 6.193 o Ciutat Vella en Barcelona 2.570 viviendas $^{36}$. Dado que los datos fueron obtenidos en Marzo de 2017 se puede presuponer que estas cifras son aún más altas en temporada alta. Pero al mismo tiempo, el simple hecho de que haya este gran número de plazas turísticas disponibles en plena temporada baja demuestra que la vivienda turística vacacional constituye un tipo de oferta que a pesar de su innegable carácter estacional inherente al turismo mediterráneo insular, es más propenso a su uso en temporada baja. Los motivos son dos: primeramente y a diferencia de las plazas hoteleras, los bajos costes actuales de tener abierta una plaza turística vacacional en invierno; y en segundo lugar, la orientación no exclusiva al sol y playa de gran parte de la vivienda turística. Por ejemplo, un turista de sol y playa no irá en invierno a Cala Galdana, pero posiblemente un turista que se aloje en Airbnb en el casco histórico de Ciutadella fácilmente pernoctará en la isla en temporada baja.

De cualquier modo, una primera característica es el rápido crecimiento de las viviendas comercializadas en Airbnb es su rapidísimo crecimiento especialmente desde 2014, mucho más rápido incluso que el vertiginoso aumento las viviendas

35 Se está asumiendo que las viviendas alquiladas en Airbnb.com no están reguladas. La base de esta presuposición es que de las 2.401 anuncios ofertados en Menorca a través de dicho portal y analizados en este trabajo, tan sólo 45 afirman tener algún tipo de licencia turística.

36 Insideairbnb.com, 2017 


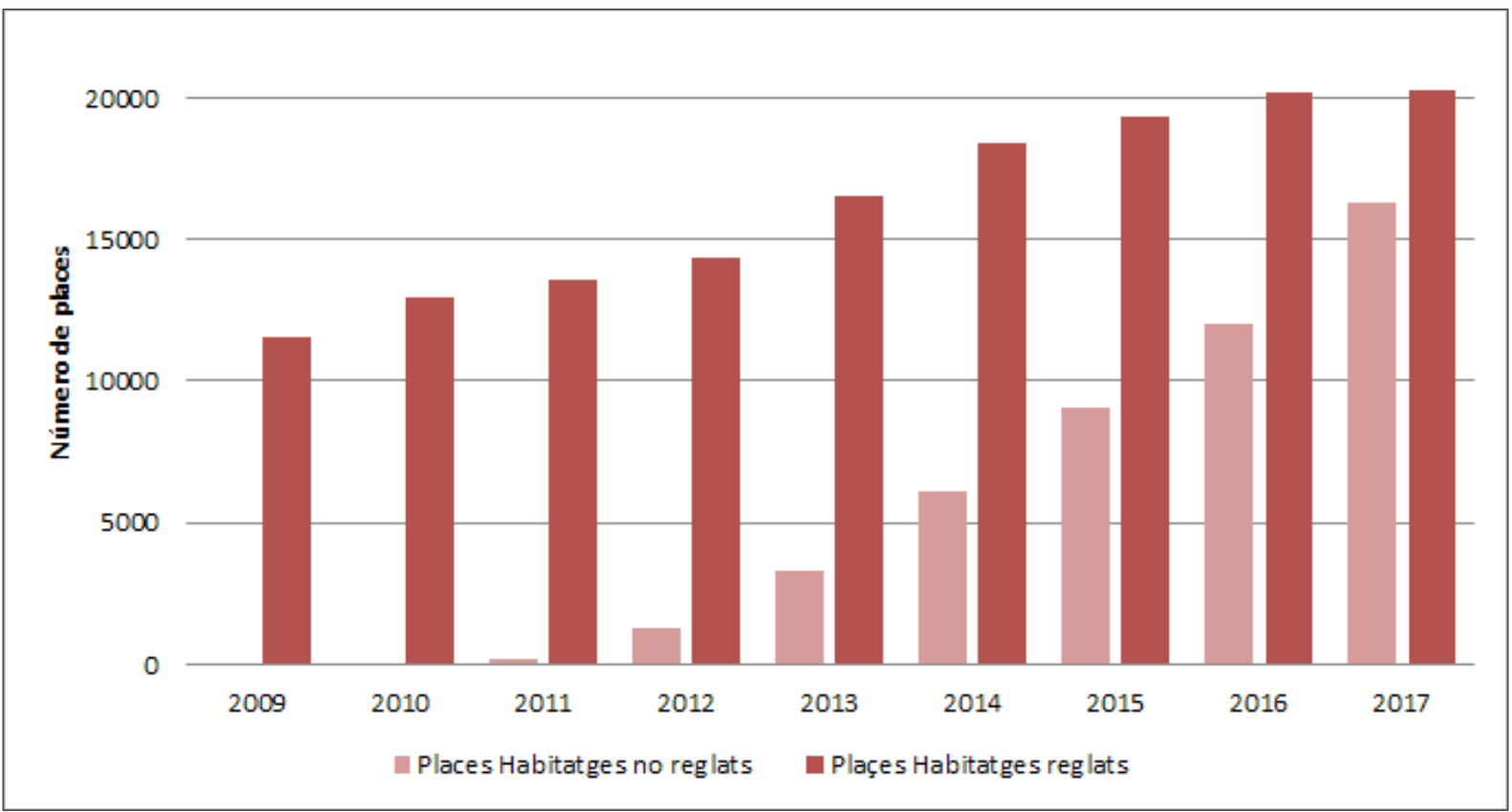

Figura 5: Comparativa plazas en viviendas regladas y en viviendas ofertadas en Airbnb. Fuente: Elaboración propia a partir de Consell Insular de Menorca (2017) y airbnb.com (2017).

turísticas regladas (figura 5). Así, sólo el total de plazas ofertadas en el portal de Airb$\mathrm{nb}^{37}$ (no regladas) cada vez se acerca más al de las plazas regladas (figura 5).

El aumento de las plazas turísticas ofertadas en el portal Airbnb ha sido exponencial desde 2012: 1.051 nuevas plazas en 2012; 2.049 nuevas plazas en 2013; 2.841 nuevas plazas en 2014; 2.923 nuevas plazas en 2015, 3.034 en 2016 y 4.218 nuevas plazas el primer trimestre 2017. Este incremento muestra es el potencial de crecimiento que todavía tiene esta aplicación, y por tanto, la posibilidad tanto de nuevas sinergias económicas y dinámicas competitivas ligadas al sector turístico , así como su potencial problemática social -como se verá en próximas secciones-.

Una segunda característica es la distribución geográfica de plazas turísticas ofertadas a Airbnb .Las viviendas turísticas están concentradas en los municipios de Maó y Ciutadella, -especialmente en este segundo municipio-y en las principales urbanizaciones turísticas de la Isla (figura 6).

A diferencia de las plazas turísticas regladas, que generalmente tienen un mayor peso en las zonas de urbanizaciones turísticas que en zonas urbanas, el patrón geográfico en el caso de las viviendas ofertadas en Airbnb no es exactamente el mismo. En este sentido, la mayor concentración de viviendas turísticas ofertadas en Airbnb se encuentra en Ciutadella, con una fortísima presencia en el núcleo histórico de dicha ciudad (una densidad aproximada de 534 plazas turísticas de Airbnb / km²). A bastante distancia aparecen urbanizaciones turísticas como son Cala en Blanes y Cala Santandria (municipio de Ciutadella) con una densidad de entre 200 y 300

37 Téngase en cuenta que el presente artículo está considerando sólo las plazas ofertadas en el portal Airbnb.com. Aunque una gran proporción de las viviendas que están ofertadas en Airbnb también lo están en otros portales similares, si se juntasen todas las viviendas turísticas ofertadas en el conjunto de portales y se comparasen con las viviendas turísticas regladas, la proporción de viviendas turísticas no regladas sería más elevada que los datos que se ofrecen aquí. 


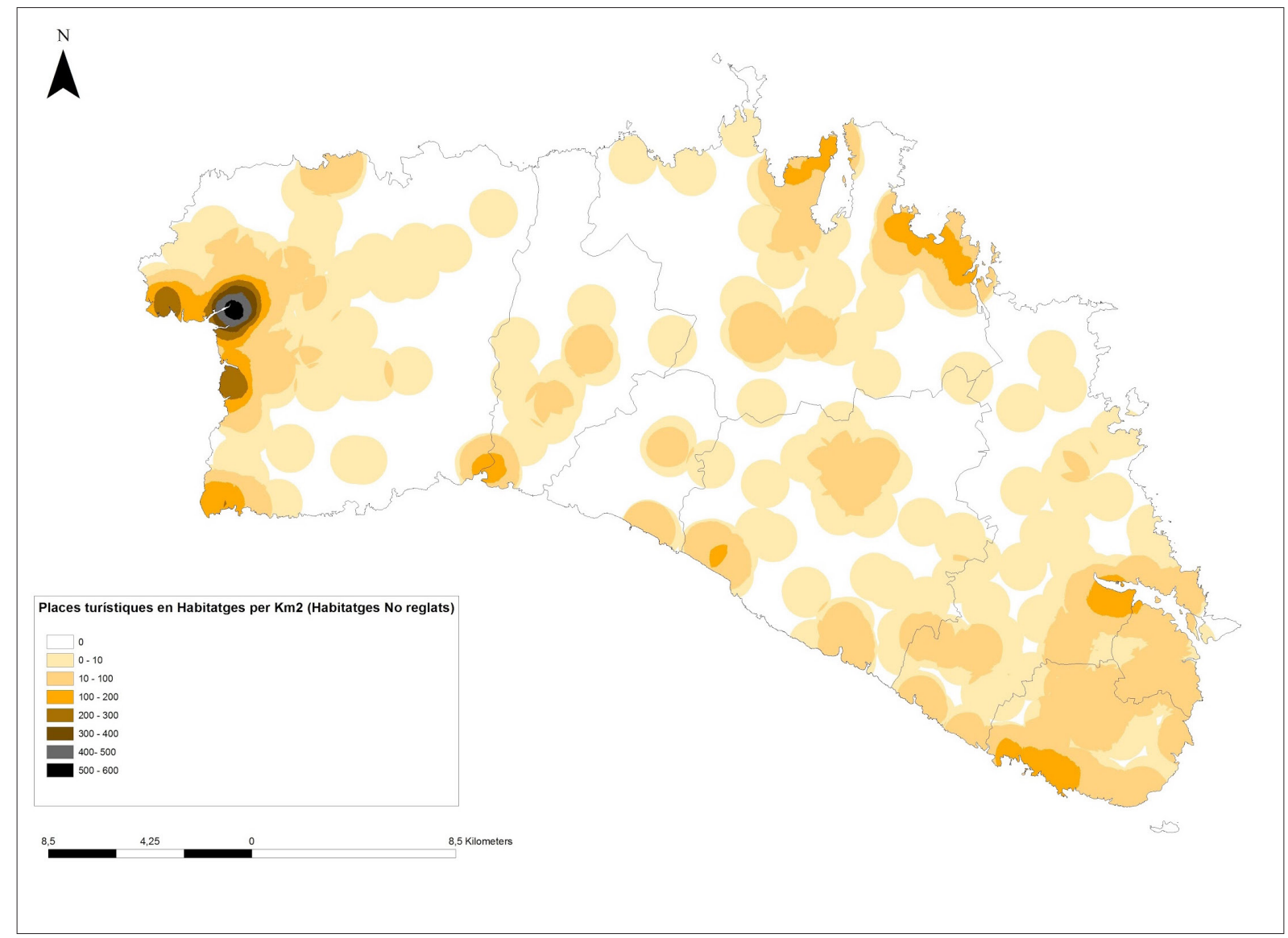

Figura 6: Densidad de plazas turísticas comercializadas en Airbnb por kilómetro cuadrado (2017) Fuente: elaboración propia a partir de Airbnb.com

plazas / km². Otros lugares importantes de la isla son Cala Galdana, Son Bou y la zona de Binissafúller y Binibéquer al sur de la isla. En el norte destacan Fornells-Playa de Fornells y la zona de s'Arenal d'en Castell y Puerto de Addaia. Finalmente, destaca también el núcleo urbano de Maó (figura 6). Así pues, la diferencia entre la distribución geográfica de las plazas turísticas en vivienda regladas -principalmente concentrada en zonas turísticas-, y las ofertadas en Airbnb -con una fuerte concentración en zonas turísticas pero también en los núcleos urbanos- viene marcada por el hecho de que la ley turística autonómica vigente hasta el verano de 2017 sólo contempla uso turístico de vivienda en unifamiliares. Pero la popularización de Airbnb ha llevado a la incorporación de todo tipo de vivienda al mercado turístico, con una nula capacidad de contención del uso turístico del parque de viviendas por parte de la administración durante el período estudiado (2010-17).

Como se puede apreciar en las ilustraciones que vienen a continuación, la proliferación y densificación de plazas a Airbnb va aumentando exponencialmente con el paso de los años, hasta irse configurando los patrones actuales. Además de una fuerte concentración en Ciutadella y otros núcleos, se produce también un continuum de altas densidades de viviendas turísticas ofertadas en Airbnb en los municipios de Sant Lluís-Es Castell y en el núcleo de Maó. Aun así, en 2017 todavía quedaban tres grandes zonas de la campiña menorquina relativamente libre de plazas turísticas ofertadas a Airbnb: una primera zona son las estribas orientales del muni- 


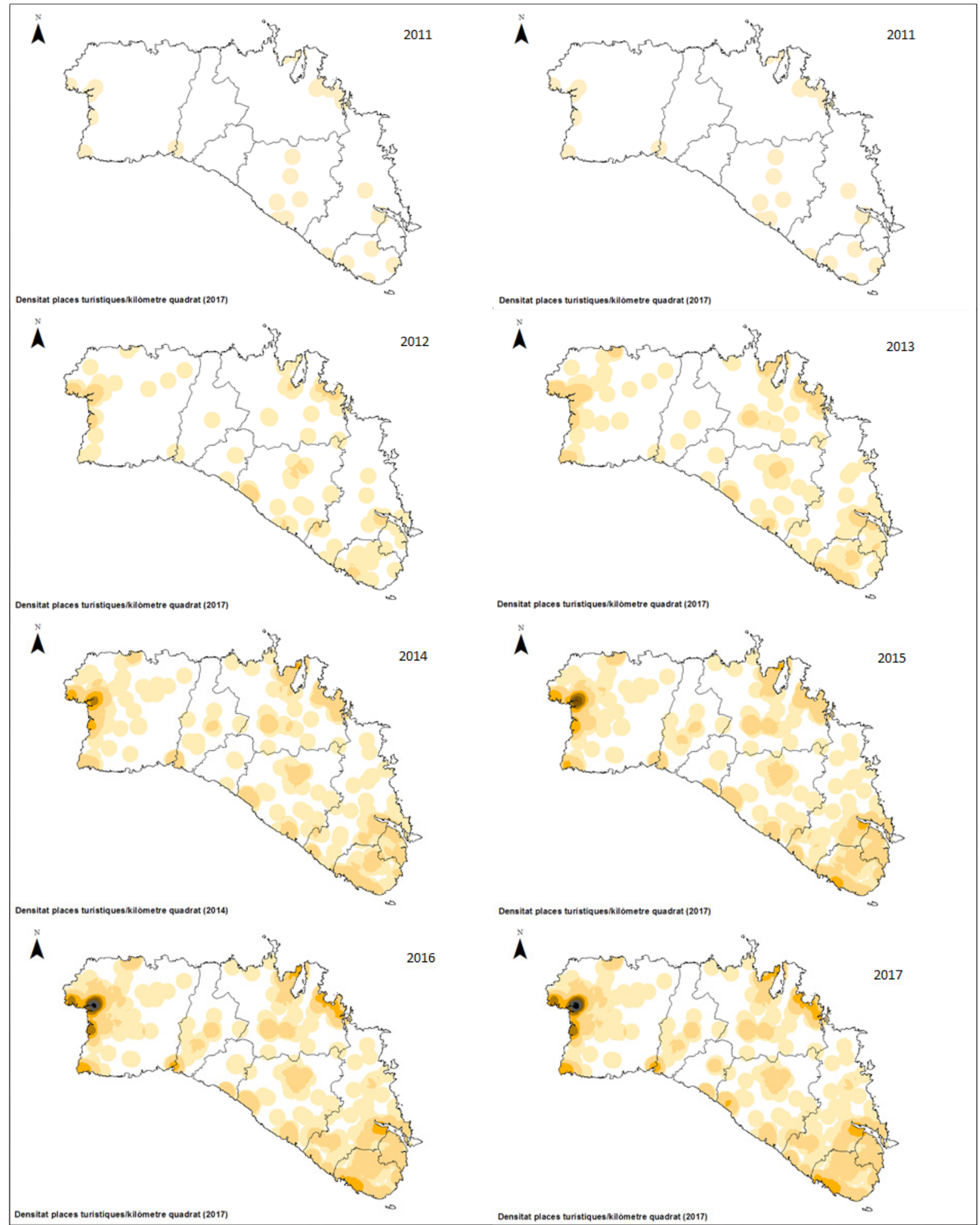

Figura 7. Evolución de la densidad de plazas turísticas ofrecidas en Airbnb / kilómetro cuadrado. Fuente: elaboración propia a partir de Airbnb.com

cipio de Ciutadella y la zona norte de Ferreries y noroeste de Es Mercadal. Otra zona se Es Migjorn Gran (con las notables excepciones de Es Migjorn Gran pueblo y Santo Tomás), y en tercer lugar, el entorno de S'Albufera des Grau (figura 7). 
Siguiendo las clasificaciones tipológicas de espacios urbanos turísticos establecidas por Patrick Mullins y Daniel Hiernaux ${ }^{38}$ se observaría un patrón dual en el uso turístico de la vivienda en Menorca, fiel reflejo del urbanismo dual menorquín explicado en el apartado anterior. Por un lado, encontraríamos las urbanizaciones turísticas como por ejemplo Son Parc o Sant Tomàs; espacios urbanos creados ad hoc para el turismo y allí donde históricamente se ha usado la vivienda como alojamiento turístico. En este sentido, la irrupción de páginas web como Airbnb lo que hace es añadir un novedoso y presumiblemente efectivo canal de comercialización. Desde un punto de vista del potencial gentrificador de espacios urbanos, el impacto del uso de Airbnb en este tipo de espacios es menor ${ }^{39}$.Por otro lado, encontraríamos los núcleos tradicionales (especialmente los de Maó y Ciutadella) que en la actualidad una expansión masiva del uso turístico de la vivienda en la totalidad de los núcleos. En efecto, la mayor parte de las viviendas turísticas ofertadas vía Airbnb están localizadas no sólo en las urbanizaciones turísticas anteriormente descritas, sino también en las dos ciudades-especialmente en Ciutadella- (véase Figura 6). Aunque el alquiler de viviendas a turistas ya existía de forma limitada en el casco histórico de Ciutadella, su extensión a la totalidad de los núcleos urbanos de la isla y su masiva proliferación sí es una novedad que ha llegado de la mano de las plataformas de alquiler. $Y$ es en estas zonas por lo tanto, donde hay mayor riesgo -al menos potencial- de gentrificación turística. Más allá de los impactos locales anteriormente descritos, existentes también en las zonas urbanas, hay un segundo tipo de impactos específicos de estas zonas urbanas, que son las alteraciones sobre la disponibilidad de la vivienda para uso residencial por parte de locales. Por lo tanto, desde la perspectiva de este estudio, es en estos núcleos urbanos donde potencialmente tienen mayor relevancia en las dinámicas de gentrificación turística.

\section{Tipología de huéspedes de Airbnb en Menorca: una aproximación}

Uno de los principales argumentos ideológicos de Airbnb es el de la ayuda a las economías locales: el local se convierte en emprendedor turístico, y hay un efecto de fortalecimiento de la economía. Este argumento puede ser especialmente significativo en países como España, donde el impacto de la crisis y las subsecuentes políticas de ajuste han precarizado fuertemente las rentas del trabajo. Ésta línea argumental es también usada por la sociedad menorquina. De las entrevistas ${ }^{40}$ que se

38 Mullins, 1991; Hiernaux , 2014

39 Obviamente, un canal de comercialización tan efectivo puede llevar a un potencial, incremento de la presión sobre los recursos energéticos y / o de abastecimiento de, agua de la Isla; así como de, incremento de tráfico o empleo de las playas isleñas. Este son sin duda, impactos que son importantes para la isla, pero que en cierto sentido, no son nuevos, en tanto en cuanto son efectos similares al del turista que se hospeda en un hotel o apartamento turístico.

40 En el transcurso de este trabajo se han realizado media docena de entrevistas en Menorca en que se han podido corroborar o matizar algunos de los argumentos usados en este artículo. Aunque la muestra no es representativa y no debe ser por tanto considerada como una fuente relevante del trabajo, sí que ha resultado ser una excelente fuente de información complementaria. 
han podido llevar a cabo en la elaboración de este trabajo, el principal motivo justificador es precisamente este: "En Menorca, la economía va a la mitad de Mallorca y no digamos de Ibiza, Airbnb ayuda a dinamizar la economía"41; "El alquiler vacacional es un complemento importante a la industria y a la agricultura" ${ }^{42}$. También se alude habitualmente a casuísticas concretas: "tengo una amiga divorciada que está pagando la hipoteca de su casa alquilando habitaciones"43. Son por tanto, perfiles de personas que "han encontrado en esta modalidad de negocio una manera de salir de la crisis tras la pérdida de su trabajo o una fuente de ingresos extra para pagar unos gastos inesperados por motivos familiares o profesionales" ${ }^{\prime 4}$. Efectivamente, este segmento poblacional existe y constituye un elemento extraordinario de justificación y de disuasión social de este fenómeno. Sin embargo, los datos cuantitativos matizan ésta extendida percepción social.

Un primer punto a resaltar es que de las 2.401 viviendas alquiladas vía Airbnb en Menorca, tan sólo 239 son en habitaciones dentro de una casa (y 15 son en habitaciones compartidas). Por lo tanto sólo el 10,54\% de aquellos que alquilan están alquilando una parte de la casa donde ellos habitan; una cifra muy menor en comparación con el 42,9\% de habitaciones que se alquilan en Barcelona o el 14\% de habitaciones compartidas en Mallorca ${ }^{45}$.

En este caso sí, se trataría por tanto de un "enriquecimiento popular" a partir del turismo ${ }^{46}$ en línea con el argumentario anteriormente descrito. La otra cara de la moneda es que el 89.46\% de las viviendas alquiladas vía Airbnb en Menorca son casas que se alquilan enteras: es decir, particulares que tienen al menos una vivienda en propiedad y que pueden permitirse el lujo de alquilar una vivienda durante unos meses del año (o durante todo el año). Efectivamente, si se alquila una vivienda entera, es porque se tiene otro lugar donde vivir; o sea, el 89.46\% de las viviendas están en manos de agentes que tienen al menos una vivienda en propiedad. Por lo tanto, se trata de un segmento social que en el contexto actual de recesión económica, tiene unas condiciones económicas relativamente solventes. No obstante, dentro de este $89.46 \%$ hay desde familias de clase media, con casos en que los ingresos adicionales obtenidos en alquiler turístico están ayudando efectivamente a pagar hipotecas hasta el caso de grandes operadoras inmobiliarias de abasto global.

¿Cómo distinguir entre estos agentes que constituyen el 89,46\%? La cantidad de viviendas que alquila cada usuario es una primera aproximación a esta realidad, que se ha complementado a partir de la información personal que a menudo se ofrece en la web de Airbnb. En este sentido, en Menorca predominan aquellos huéspedes que sólo alquilan una casa: (un 47\% de las viviendas alquiladas siguen

41 Entrevistado 1, 12-04-2017

42 Entrevistado 2, 12-4-2017

43 Entrevistado 1: 12-04-2017

44 Galán, 12/04/2017

45 Insideairbnb.com, 2017

46 Aunque en España el re-alquiler de una casa en régimen de alquiler está prohibido por la ley de Arrendamientos Urbanos, diversos entrevistados afirman que algunos inquilinos en los centros de Maó y Ciutadella re-alquilan habitaciones de su casa a turistas. 
este patrón). Por lo tanto, el actor no profesional es todavía muy importante en la estructura del alquiler de viviendas en Menorca. A pesar de la variedad existente de huéspedes, hay una dualidad clara entre aquellos profesionales y aquellos no profesionales del sector. A grandes rasgos, la división es del 50-50.

La casuística más común de este tipo de propietario se corresponde con clases medias que alquilan una segunda o tercera residencia; con unos ingresos adicionales vía alquiler turístico que sirven para complementar otras fuentes de ingresos. Sorprendentemente, hay una concentración de esta tipología de huéspedes en las zonas urbanas -Maó, Ciutadella y otros núcleos-. Dentro de este grupo, es común que haya muchos huéspedes que vivan en Barcelona, Palma u otros lugares fuera de la isla y que alquilan su segunda residencia menorquina. El perfil de huésped urbano es por tanto -todavía- escasamente profesionalizado. Así, si de media en Menorca el $47 \%$ de las viviendas alquiladas son de huéspedes que solo alquilan una vivienda, este porcentaje aumenta en el caso de Maó (63\%) y Ciutadella con un 60\% (figura 8).

Por otra parte, el resto de anuncios (53\% en el conjunto de la isla, $40 \%$ en Ciutadella y $37 \%$ en Maó) se corresponden con actores que tienen más de una casa para alquilar (figura 8). A escala insular, entre aquellos que tienen 2 anuncios ( 14\%) alquiladas en Airbnb hay una mezcla de actores profesionales, así como perfiles de clases acomodadas que aprovechan la gran demanda de viviendas turísticas para alquilar inmuebles de su propiedad. Sin embargo, a partir de 3 y 4 anuncios en adelante ( $39 \%$ de las casas anunciadas en el conjunto de la isla) se trata de actores totalmente y únicamente profesionales. Normalmente son empresas inmobiliarias que $o$ bien están especializadas en alquiler turístico desde antes de la aparición de Airbnb o bien son empresas inmobiliarias que antes de la crisis estaban especializadas en compraventa de viviendas y que con la bajada del mercado han reorientado su negocio hacia el alquiler turístico. Generalizando, este tipo de huéspedes están más bien en las urbanizaciones litorales y son muy minoritarios en Maó y Ciutadella. Aun así, se está detectando una creciente incursión de estas inmobiliarias en las dos urbes menorquinas; con alguna vivienda en los respectivos cascos históricos complementando un portfolio más amplio en zonas litorales. Entre aquellos actores profesionales se pueden distinguir dos patrones geográficos que se corresponden con dos tipologías distintas de profesionales. Por una parte están aquellos agentes que tienen un portfolio de viviendas para alquilar en un lugar determinado en Menorca y por otra parte están aquellos actores que tienen una cartera de viviendas para alquilar en todo el mundo. Los primeros se corresponden con intermediarios que se han hecho con una porción significativa del mercado del alquiler turístico en una zona determinada: por ejemplo está el caso de un huésped que oferta 54 viviendas sólo en la zona de Fornells, u otro que controla una quincena de viviendas en Cala Galdana. Los segundos son aquellos que tienen una cartera modesta en Menorca (normalmente menos de 10 viviendas) pero muy potente a nivel global (entre 100 y 400 viviendas) y con una especialización geográfica en unifamiliares en islas o zonas costeras de espacios litorales y / o insulares del Mediterráneo y Caribe. 
Un ejemplo paradigmático es el de un agente que alquila 22 viviendas en Menorca pero que cuenta con un portfolio de más de 340 viviendas más para alquilar en Mallorca, Malta, Fuerteventura, Lanzarote y en multitud de islas griegas como Skopelos, Kefalonia, Megalinisi. Corfú o Creta.

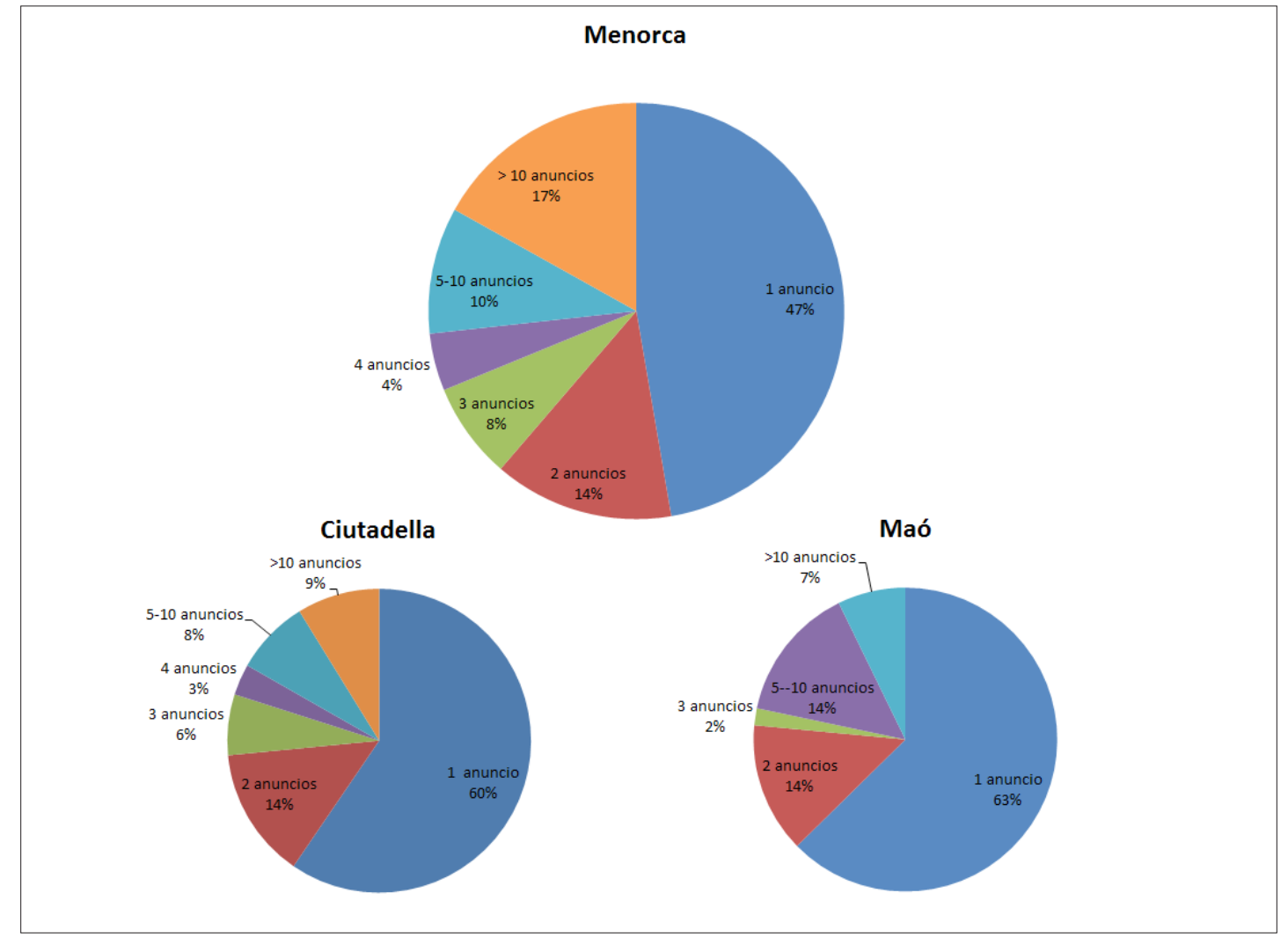

Figura 8: Porcentaje del número de anuncios anunciados por Huéspedes en Airbnb en Menorca, Ciutadella y Maó.

Fuente: elaboración propia a partir de Airbnb.com

En resumidas cuentas, nos encontramos con tres tipologías principales de actores. En primer lugar, está aquel tipo de actor no profesionalizado, que alquila una habitación; una o dos casas (nunca más de tres casas), que tiene un perfil oportunista, con casas normalmente ubicadas en cascos urbanos o zonas rurales no turísticas, y con unas rentas obtenidas del alquiler que tienden a servir como complemento de otras fuentes de ingresos. En segundo lugar tenemos aquellas empresas menorquinas que están especializadas en el sector inmobiliario. Dentro de este cajón se encuentran desde aquellas empresas constructoras inmobiliarias dedicadas tradicionalmente a la compraventa y reconvertidas a empresas de alquiler turístico; aquellas empresas tradicionalmente ligadas al alquiler turístico en la isla o intermediarios del sector turístico especializados en una zona geográfica en particular. Finalmente están aquellas grandes empresas especializadas en el negocio del alquiler turístico a nivel europeo y mundial. Son empresas que tienen un mínimo de 50 casas para alquilar entre Menorca y otros lugares con un mercado turístico similar. La presencia de este tipo de actores es especialmente relevante en tanto que mues- 
tra el crecimiento de Menorca como una pieza geográfica cada vez más importante entre los destinos de alquiler vacacional al Mediterráneo.

La tipología de actores así como su operacionalización en la isla tiene una paradoja interesante: en algunos casos de oleadas anteriores de gentrificación turística, se ha vinculado estos procesos a grandes capitales ${ }^{47}$. Similarmente, se ha asociado el presente proceso de Airbnbificación con grandes operadores ${ }^{48}$. Sin embargo, el caso menorquín lo que muestra es que los grandes operadores operan principalmente en las urbanizaciones turísticas, mientras que en las áreas urbanas de Maó y Ciutadella son los pequeños actores los que dominan. Por tanto, la gentrificación turística que tiene lugar especialmente en zonas urbanas tiene un carácter mucho más popular y menos institucionalizado que en anteriores procesos de gentrificación turística.

\section{El impacto de la irrupción de Airbnb sobre el mercado del alquiler residencial}

¿Cuál es pues, el potencial gentrificador - o no- de este uso turístico del alquiler? Como ya se ha apuntado, no se considera que los efectos clásicos de la gentrificación sean especialmente relevantes en las zonas turísticas -precisamente por su naturaleza turística y no residencial- .

Pero cómo se explica a continuación, el alquiler turístico tiene importantes efectos en el entramado urbano-residencial de la isla en tanto que el alquiler turístico de viviendas compite con el mercado del alquiler residencial por el parque de viviendas. Además, la presumible diferencia de plusvalías entre el alquiler turístico y el alquiler residencial puede llevar o bien al incremento de los precios del alquiler residencial o bien al descenso del número de viviendas residenciales disponibles para alquilar. Paradójicamente, en el caso menorquín las áreas con potencial gentrificador mayor son en donde -de momento- no operan los grandes actores inmobiliarios. ¿Cómo puede ser pues, que una serie de actores no profesionales; gente que alquila su segunda o tercera residencia supongan una disrupción del mercado de la vivienda destinado a los locales? ¿Se puede hablar de tal disrupción? El primero de marzo de 2017, había 2.401 viviendas disponibles para alquilar en la página web de Airbnb ${ }^{49}$. En cambio, el número de viviendas de alquiler residencial en la página web de idealista.com fue este mismo mes de 69 viviendas. En otra plataforma de alquiler residencial, fotocasa.es; el número de viviendas residenciales anunciada era de 52 (¡con algunos de estos anuncios repetidos en Idealista.com y Fotocasa.es!). Esto nos da una idea de la ratio de viviendas disponibles en el mercado del alquiler para uso turístico frente al uso residencial. Haciendo números gruesos, se puede afirmar que en Menorca, por cada vivienda que hay disponible para alquilar en el mercado residencial hay 20 viviendas disponibles en el mercado turístico. Estas ci-

47 Lees, 2003; Lin, 2008

48 Terraferida, 28/03/2017

49 Se asume aquí que el uso que se hace de los anuncios de la web de Airbnb es exclusivamente turístico. 
fras por sí solas indican la potente disrupción que Airbnb supone sobre el mercado del alquiler residencial.

Esto no quiere decir que si no existiera Airbnb las 2.401 casas estarían necesariamente en el mercado de alquiler residencial, ya que de estas 2.401 viviendas, sólo 969 están ubicadas en zonas urbanas y rurales residenciales; el resto está en zonas que de siempre han sido turísticas. Posiblemente, incluso sólo considerando estas 969 viviendas en zonas tradicionalmente residenciales, no todas estarían disponibles en el mercado de alquiler residencial si plataformas como Airbnb no existieran, puesto que Airbnb está también poniendo en el mercado del alquiler viviendas vacías que anteriormente no se alquilaban. Pero no es menos cierto que la cuestión de la escasez de viviendas de alquiler ha ido a la par que las viviendas ofertadas en Airbnb ha aumentado ( son casos paradigmáticos Barcelona, Palma o Eivissa). Incluso en Menorca, la prensa local ha reflejado esta escasez de viviendas ligada a viviendas turísticas. En los últimos tiempos, y especialmente desde 2016 han comenzado a proliferar indicadores en las páginas de anuncios por parte de las inmobiliarias con anuncios tales como "Por demanda de Nuestros clientes, precisamos de todo tipo de propiedades en alquiler"50. Además, los anuncios disponibles en las hemerotecas de los diarios insulares, se han reducido considerablemente desde 2010 (cuando comenzó a operar Airbnb en Menorca).

Más allá de las fluctuaciones numéricas en el mercado de viviendas a alquilar, un punto clave es el incremento de los precios del alquiler residencial ¿Es relevante este aumento de precios en el caso de Menorca? La prensa local afirma que ha habido un aumento de los precios de la vivienda de entre un 10 y un $25 \%$ sólo en el año $2016^{51}$. Según estas mismas informaciones, los pisos ya estarían a niveles de precios de antes de la crisis; y estarían subiendo "porque hay mucha demanda y no hay pisos (...) cada día nos entran unos diez clientes pidiendo a vivienda del alquiler, si tuviéramos 50 pisos los alquilaríamos, pero no tenemos"52. A finales de marzo del 2017, nuevas noticias de prensa reflejaban las dificultades del empresariado hotelero para contratar trabajadores de temporada debido a la falta de viviendas en régimen de alquiler y sus altos precios. Así, la Asociación Hotelera de Menorca estaría contactando con las empresas inmobiliarias para acoger a los trabajadores de temporada ${ }^{53}$. Esta falta de viviendas en el mercado del alquiler residencial ha repercutido en una subida de los precios del alquiler en la isla. Entre 2010 y 2016 hubo pequeñas variaciones al alza y a la baja, seguido de un incremento muy importante -y como veremos, matizable- a principios de 2017 (meses de enero-febrero) -véase figura 9- . La cuestión es saber hasta qué punto este incremento en los precios del alquiler residencial es atribuible o no a una proliferación de viviendas de alquiler turístico.

50 Diari de Menorca, 15/08/2016

51 González, 04/12/2016

52 Directora comercial de inmobiliaria citada en González 04/12/2016

53 Soler, 23/03/2017 
El aumento de los precios de alquileres residenciales del 2016 al 2017 en Menorca (y en Maó) está basado en el aumento relativo de las ofertas de casas y chalets que se alquilan con base mensual en zonas turísticas en comparación con el descenso del número de pisos en régimen de propiedad horizontal que se alquilan con base mensual en Maó y Ciutadella. Este hecho es sumamente paradójico: cada vez hay más chalets turísticos disponibles para alquilar a residentes - o como mínimo, para alquilar con base mensual-, mientras que las viviendas plurifamiliares al uso escasean para los residentes. Una explicación plausible a dicha paradoja radica en el hecho que las casas y chalets en Menorca seguramente tienen un fácil alquiler turístico en verano pero no en invierno, mientras que las viviendas plurifamiliares ubicadas en zonas urbanas céntricas tienen una alta demanda todo el año. Dicho de otro modo, el turista que alquila en invierno una casa en Menorca está probablemente más interesado en alquilar una casa en el centro histórico de Maó o Ciutadella o en su defecto, en zonas residenciales más o menos cercanas a espacios urbanos, que en alquilar por ejemplo un chalet en una urbanización turística como por ejemplo Binibéquer o Puerto de Addaia .

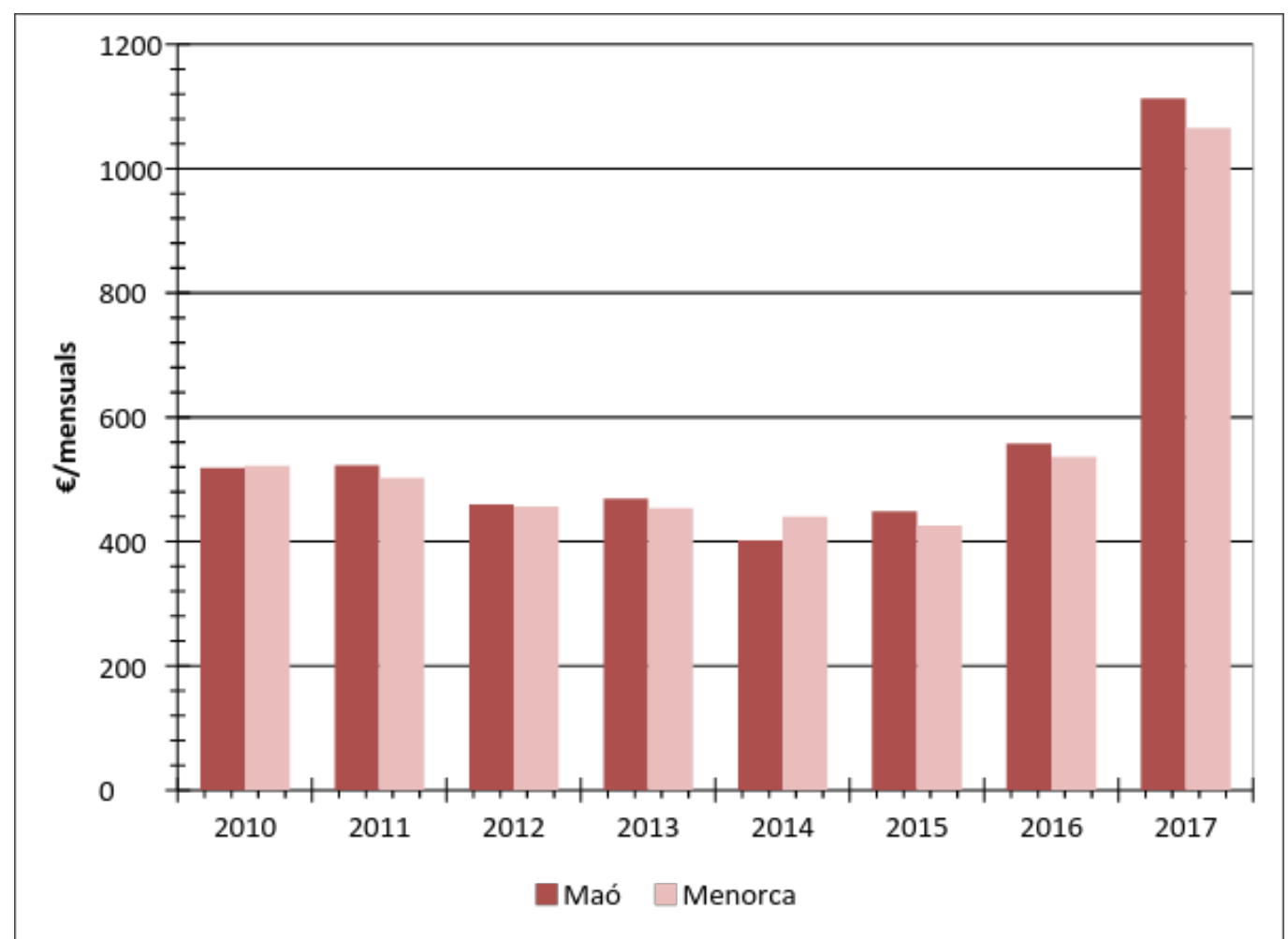

Figura 9: Evolución del precio medio mensual del alquiler de vivienda residencial en Menorca y Maó.

Fuente: elaboración propia a partir de la hemeroteca de Diari de Menorca.

En efecto, el ímpetu del turismo urbano fuera de temporada facilita que muchos pisos plurifamiliares dejen de estar disponibles para alquiler residencial durante todo el año; mientras que el fuerte componente estacional de los chalets hace que muchos de estos chalets se alquilen con base mensual en la temporada baja. Esta gran presencia de chalets disponibles para alquilar a residentes en comparación con 
pisos es lo que explica incremento de precios del alquiler residencial tan repentino del 2017 mostrados en la figura anterior. Simplificando, ya no quedan pisos de 50 metros cuadrados para alquilar a residentes en el centro de Maó o Ciutadella, pero hay chalets por 3.000 euros disponibles para alquilar en temporada baja en cualquier urbanización turística del litoral menorquín.

Recapitulando: tenemos un descenso de viviendas disponibles para alquilar a residentes y un aumento de viviendas disponibles para turistas. Sólo esto lleva a un encarecimiento de los precios del alquiler residencial. Pero este encarecimiento en el mercado residencial es todavía mucho más marcado por el hecho de que las viviendas que el mercado de Airbnb "roba" al mercado de alquiler residencial son viviendas plurifamiliares ubicadas en núcleos urbanos. De este modo, hay una disminución radical del mercado de alquiler residencial de plurifamiliares urbanos, pero en cambio, los chalets de lujos que en verano se alquilan a turistas se siguen ofertando a residentes en el invierno. Esto hace que la media de precios del mercado de alquiler residencial aumente considerablemente.

En el caso de Maó, hay un descenso del número de pisos disponibles para alquiler. Esto se ha podido constatar cuando se ha trabajado con los anuncios de la prensa en papel menorquina: si para el año 2010 cada día había del orden de 10 anuncios de alquiler, desde 2015 en adelante a duras penas se puede encontrar un anuncio al día. Además, los precios de alquiler también han subido espectacularmente en el municipio. Así, en el conjunto de viviendas, los precios en el municipio de Maó se habrían duplicado entre 2016 y 2.017: los $557 €$ / mes de media en 2016 se habrían convertido $1.065 € /$ mes en 2017. Pero si sólo se consideran plurifamiliares (o no se tienen en cuenta los chalets, villas, y pisos de lujo de 5 o más habitaciones) el incremento es mucho menor: se habría pasado de $557 € /$ mes a $665 € /$ mes. Esta cantidad es sensiblemente inferior a los $1.065 €$ anteriormente citados, y viene a demostrar que el aumento de precios en el mercado de vivienda residencial viene marcado por el aumento relativo de la oferta de chalets de relativo lujo en relación con el de viviendas plurifamiliares ; puesto que estas últimas pasan a estar sólo disponibles vía Airbnb o plataformas similares.

¿Porque pues, se produce este doble proceso de incremento de los precios de las viviendas residenciales y de falta de alquiler de plurifamiliares? La hipótesis es obvia: las rentas que se pueden obtener de un alquiler turístico - que recordamos se alquilan diariamente- son en principio mucho mayores ${ }^{54}$ que las rentas que se pueden obtener a nivel mensual. Así, si se multiplican los precios diarios de Airbnb en Menorca por treinta días y lo comparamos con los precios mensuales del alquiler residencial en la isla, la diferencia es muy grande, aunque es una diferencia decreciente por los motivos que se explicarán a continuación. Pero hay un punto clave que

54 Un argumento muy común usado por la plataforma Airbnb y los huéspedes que realizan alquiler turístico es que éste tipo de alquileres conlleva una serie de costes (p.e. limpieza, mantenimiento de mobiliario) que no existen en el alquiler residencial. No obstante, debe recordarse que el alquiler residencial también tiene costes para el propietario -como por ejemplo, de mantenimiento, intermediación- que también afectan a las rentas obtenidas. 
puede distorsionar enormemente esta teoría: el alquiler turístico, a diferencia del alquiler residencial, no necesariamente está alquilado a turistas los treinta días del mes, puesto que está sujeto a la fluctuante demanda diaria. Para este trabajo, se ha calculado la diferencia de precios mensuales entre el alquiler turístico y el alquiler residencial asumiendo tres escenarios diferentes de ocupación para el alquiler turístico: a) ocupación media del alquiler turístico de 28 días / mes; b) ocupación media del alquiler turístico de 14 días / mes y c) ocupación media del alquiler turístico 7 días / mes. En este sentido, los tres escenarios son realistas en un destino turístico de primer orden como es Menorca, y se podrían corresponder con un escenario de temporada alta, un escenario de transición de temporada alta a temporada baja y un escenario de temporada baja.

Lo que se puede apreciar son dos elementos clave (figura 10). En primer lugar, una gran diferencia entre los precios mensuales que se obtienen entre el alquiler residencial y el alquiler turístico desde 2010 hasta la actualidad, en los tres escenarios de ocupación descritos. En segundo lugar, hay una reducción en el precio medio del alquiler turístico desde 2010 hasta la actualidad, que contrasta con el aumento de los precios del alquiler residencial. Esta tendencia a la baja de los precios de alquiler turístico y al alza del alquiler residencial llega hasta tal punto de que con un escenario de ocupación de una vivienda de Airbnb de 7 días al mes, para el año 2017 los precios mensuales residenciales serían ligeramente superiores a los precios de la vivienda vacacional.

¿ Cómo se explica este descenso sostenido de los precios medios del alquiler turístico con una popularización del alquiler turístico por parte de los propietarios rentistas y la consiguiente subida del número de viviendas que forman parte del alquiler turístico? Precisamente un factor no se explica sin el otro. En 2010, tan sólo había 17 viviendas alquiladas vía Airbnb. Eran viviendas turísticas de alto lujo y que ya tenían una función turística antes de la irrupción de esta plataforma web. Conforme han ido pasando los años, no sólo se han ido ofertando viviendas de lujo, sino también todo tipo de viviendas, que obviamente, no se alquilan a los mismos precios que las mansiones de lujo, sino a precios más bajos. Desde 2010 hasta la actualidad se han ido incorporando no sólo viviendas turísticas en urbanizaciones, sino también viviendas que históricamente tenían un uso residencial en zonas urbanas y rurales. Y conforme la cartera de viviendas de la página web de Airbnb y su diversidad ha aumentado, también los precios medios de las viviendas ofrecidas en esta página web han ido necesariamente disminuyendo. Inversamente, conforme el mercado de viviendas residenciales de alquiler ha disminuido en favor del mercado de alquiler turístico, el efecto en el mercado residencial ha sido inverso. Si en 2010, cualquier tipo de vivienda estaba en el mercado del alquiler residencial, en $2017 \mathrm{el}$ mercado se ha reducido casi exclusivamente a la vivienda de lujo que no puede ser alquilada a turistas.

Y precisamente esta transición desde un mercado residencial a un mercado de lujo es lo que ha hecho que los precios hayan aumentado en 2016 y sobre todo en 
Escenario 1: Comparativa precios alquiler residencial y alquiler turístico (asumiendo una una ocupación en el alquiler turístico de 28 días/mes)

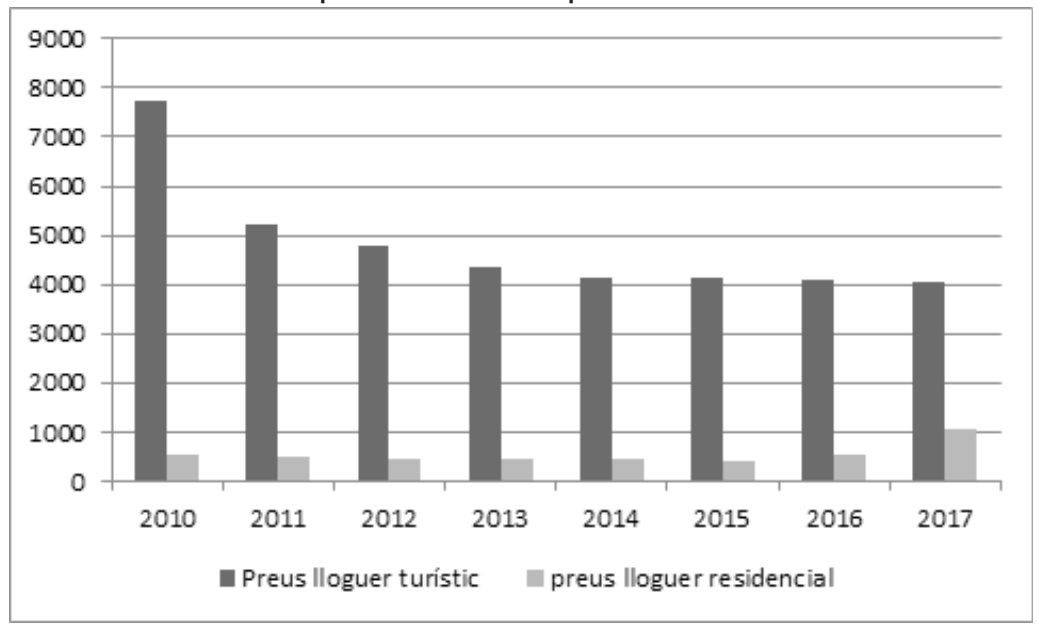

Escenario 2: Comparativa precios alquiler residencial y alquiler turístico (asumiendo una ocupación en el alquiler turístico de 14 días/mes)

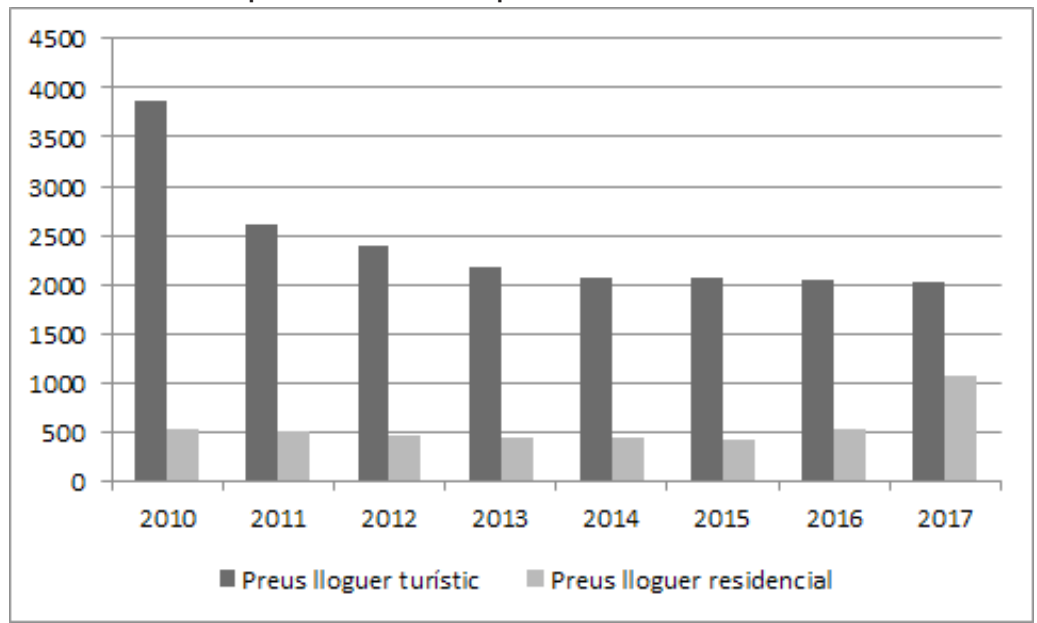

Escenario 3: Comparativa precios alquiler residencial y alquiler turístico (asumiendo una ocupación en el alquiler turístico de 7 días/año)

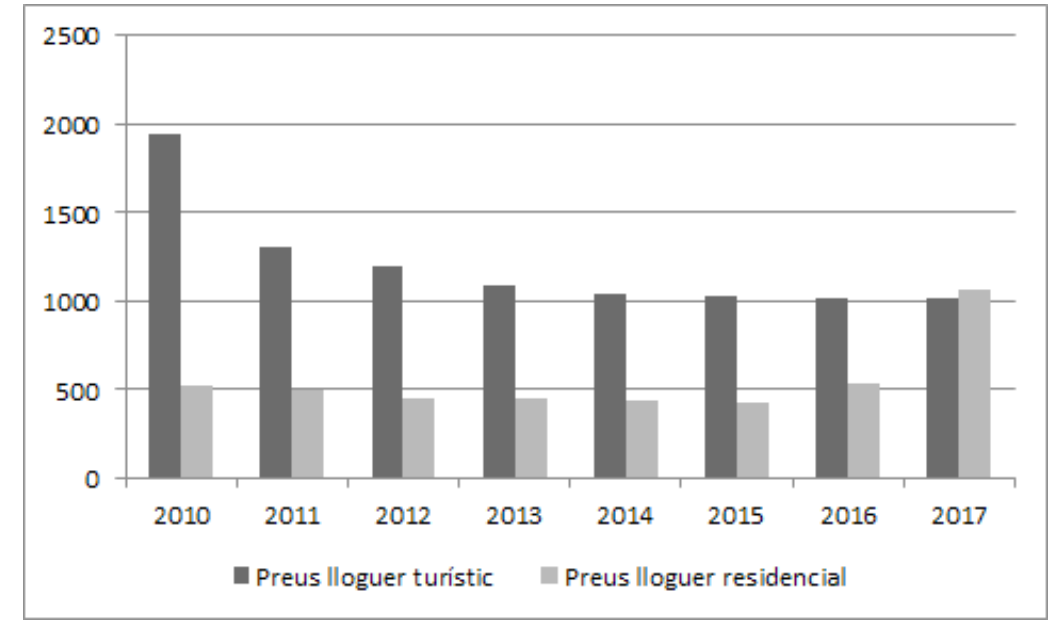

Figura 10. Comparativa entre los precios de alquiler residencial y alquiler turístico. Fuente: elaboración propia a partir de Airbnb.com (2017) y Hemeroteca de El Diari de Menorca. 
2017 (véase Figura 9). Este aumento de precios también está provocado por el hecho de que muchas viviendas unifamiliares de relativo lujo tienen una doble función turística y residencial a lo largo del año: cuando las bajas ocupaciones de la temporada baja hace que no sea rentable alquilar a turistas se alquila a residentes ${ }^{55}$. Esta doble función también empuja al alza los precios de alquiler residencial, ya que a la mínima que estos no son altos, le resulta más rentable al propietario alquilar la vivienda vía Airbnb, aunque sea por unos pocos días al mes. De hecho, una de las características de las relaciones entre el mercado de alquiler vacacional y el mercado de alquiler turístico es su permeabilidad: las viviendas pueden pasar de ser alquiladas mensualmente a diariamente sin ningún tipo de impedimento.

Una última cuestión es hasta qué punto llegará esta eclosión de viviendas turísticas y cuáles serán sus potenciales implicaciones. El mercado de viviendas en Airbnb comienza a mostrar síntomas claros de sobreoferta: la oferta ha aumentado masivamente y lo sigue haciendo cada año con más intensidad a la par que los precios disminuyen. Aun así, este uso turístico tiene todavía perspectivas de crecimiento. Tal vez menos en el segmento de chalets de lujo, donde la inmensa mayoría del parque de la isla se alquila ya por Airbnb, pero sí en el resto de tipologías de viviendas, tanto rurales como urbanas.

Si bien Ciutadella está ya colapsada como otros cascos históricos de otras ciudades insulares; el resto de cascos urbanos y muy especialmente Maó tienen grandes perspectivas de crecimiento. Maó tiene la tiene la característica única en toda la isla que es un parque de viviendas vacías y segundas residencias -2.760-, inferior al número de viviendas ocupadas en régimen de alquiler -3.175-56. Es también donde hay un mayor número de viviendas alquiladas a residentes en toda la isla. En todo caso, el número de viviendas alquiladas vía Airbnb en la actualidad (261) es mucho menor que el parque de viviendas en régimen de arrendamiento; pero existe el peligro real de que este parque de viviendas en alquiler residencial pasen a ser parte del alquiler turístico ya sea por no renovación de contrato o por aumentos inasumibles de precios. Ya es significativo que el número de viviendas alquiladas en el casco urbano ( 143 ) supera a las viviendas unifamiliares alquiladas en el resto del municipio (118). Esto indica el fuerte reclamo urbano del turismo en Maó, y por tanto del potencial gentrificador de Airbnb.

En otras palabras, la vía de expansión futuro del alquiler turístico en los próximos años en la isla no serán tanto las vivienda típicamente turísticas en tanto éstas ya están casi en su totalidad comercializadas por plataformas como Airbnb y similares, sino la vivienda residencial plurifamiliar: aquella ubicada en los cascos urbanos, y también en las zonas rurales de la isla. Esta incorporación -que ya está ocurriendo- no sólo puede privar a ciertos estratos de la población local (familias de

55 Coincidiendo con el inicio de la temporada baja en Menorca, hay un movimiento de trabajadores del sector público (principalmente profesorado de educación primaria y secundaria) que acuden a trabajar a la isla, normalmente con contratos temporales y que por tanto dinamizan el mercado de alquiler residencial.

56 INE, 2011 
bajos ingresos, jóvenes emancipados, emigrantes o trabajadores públicos) de acceso a nuevas viviendas de alquiler, sino que también tiene el riesgo real de desplazar a la población, en tanto en cuanto la renovación de los contratos de alquiler puede no producirse se (la vivienda se reconvertida a vivienda turística) o bien las renovaciones se producen con un considerable aumento de precios que el inquilino no puede asumir.

\section{A modo de conclusión}

El trabajo demuestra que la aparición de Airbnb ha provocado un aumento sustancial de las plazas turísticas (no reguladas) en viviendas, lo cual ha provocado que el conjunto de plazas turísticas en viviendas haya llegado a superar las plazas hoteleras y de apartamentos turísticos como principal oferta de alojamiento en la isla. La mayor parte de las hipótesis de partida del trabajo se han visto confirmadas: Airbnb ofrece un nuevo canal de comercialización para viviendas que ya tenían previamente un uso turístico en Menorca, pero a la vez la irrupción de dicho portal ha provocado la incorporación de nuevas plazas turísticas en zonas urbanas. Además, se ha confirmado que el aumento de precio en el alquiler residencial está íntimamente ligado a la proliferación de viviendas turísticas.

De esta forma, existen elementos clave que demuestran el inicio de un proceso de gentrificación turística; por un lado la falta de oferta de vivienda para alquilar a residentes, y por otro, el aumento de precios de alquiler debido a la irrupción de las plataformas de alquiler turístico. De cualquier modo, estas dinámicas no son una novedad de éste proceso de Airbnbficación. Lo que ciertamente representa una singularidad es que esta gentrificación turística no esté basada en una fuerte intervención público-privada basada en megaeventos o proyectos de desarrollo urbano, sino que esté causada por una disrupción tecnológica. En efecto, el papel central de las nuevas tecnologías y el papel no-proactivo de la administración pública en este tipo de procesos sí que es una novedad en este tipo de dinámicas.

Enmarcando los procesos explicados en la concepción inicial de gentrificación de Smith (1979), cabe plantearse si la subida de precios de alquiler residencial y la desaparición del mercado del alquiler están ya produciendo gentrificación o si bien son elementos indispensables, pero no suficientes, para que las dinámicas gentrificadoras actúen en un futuro muy próximo. En principio, los datos aportados en el artículo por sí solos no implican que la gentrificación se esté ya produciendo: la subida de los precios y la contracción del mercado del alquiler residencial no afecta (a corto plazo) a aquellos inquilinos que tienen contratos de alquiler vigentes (aunque sí que les afectará cuando los contratos expiren). Sin embargo, la irrupción de Airbnb no sólo tiene un potencial gentrificador en aquel parque de vivienda que ya está alquilado, sino que el sólo hecho de que las viviendas ofertadas para alquilar se trasvasen del mercado del alquiler residencial al turístico y que suban de precio necesariamente implica que la gentrificación turística no es solo un fenómeno potencial, sino también presente. El sólo hecho de poner viviendas en alquiler en Airbnb 
para turistas y no a residentes, así como la subida de precios produce gentrificación de manera inmediata, puesto que muchos de los residentes que quieran mudarse a núcleos urbanos no pueden hacerlo bien por precios no asequibles bien por falta de oferta, produciéndose así una proceso de desplazamiento indirecto de aquellos residentes que buscan arrendar vivienda.

Además, la irrupción de Airbnb no sólo está poniendo en riesgo el derecho a la vivienda de muchos residentes, sino que puede llevar a cierta fractura social en la isla. Esto es debido al segundo elemento singular de la isla, que es el carácter eminentemente "popular" de los procesos de gentrificación turística en Maó y Ciutadella. Así, el agente gentrificador no es un gestor de viviendas o una gran inmobiliaria como sí pasa en las urbanizaciones turísticas de la isla, sino que es el vecino de la puerta de al lado. Así, ésta gentrificación turística "popular" está llevando a un desgarro de la costura (el acceso a la vivienda) que cose a la clase media menorquina, en tanto el turismo y el horizonte lucrativo que abre Airbnb está provocando que parte de clase media se enriquezca y que parte de clase media tenga dificultades cada vez mayores de acceso a la vivienda.

Hay un elemento adicional importante en el caso de airbnbficación menorquina. La isla es conocida por su talante proteccionista (al menos en comparación con el resto del archipiélago balear y el levante español). Uno de los estandartes del proteccionismo menorquín ha sido el establecimiento de un techo al desarrollo hotelero y una congelación de las nuevas urbanizaciones. Pero silenciosamente y con el beneplácito de gran parte del establishment insular, la irrupción del fenómeno de Airbnb ha dinamitado al alza el vanagloriado techo de plazas, aumentando considerablemente la presión turística sobre la isla. Ante esta situación y no sin un considerable debate sobre la estrategia a seguir y con erráticos bandazos en la política de la consejería de turismo autonómico, el gobierno balear aprobó en agosto del 2017 una nueva ley turística que se interpretó como restrictiva respecto al alquiler turístico. Esta ley restringe el alquiler en viviendas plurifamiliares que no sean vivienda principal del huésped, y establece una serie de sanciones en caso de incumplimiento, así como un generoso techo global de plazas turísticas en viviendas. En todo caso, se deja en manos del Consejo Insular de Menorca y de los ayuntamientos la adecuación de los parámetros autonómicos a la realidad insular. Como ya está pasando en el caso de Barcelona, un elemento clave será ver hasta qué punto la administración es capaz de controlar la oferta de Airbnb, y ejecutar los respectivos regímenes sancionadores. Así mismo, cabe destacar que dicha ley establece un elemento que puede ayudar a ralentizar considerablemente las dinámicas de gentrificación turística en zonas urbanas. En efecto, no se podrá alquilar en plurifamiliares, lo cual sin duda ayudará a revertir la actual contracción del mercado del alquiler residencial y su subida de precios. En cambio, e inspirándose en el caso de ciudades como Berlín o Amsterdam, sí que se podrá llevar a cabo, con un máximo de 60 días, en aquellas viviendas plurifamiliares que sean primera residencia. Es decir, aquellas familias que usen el turismo como una fuente complementaria de ingresos sí que 
tendrán la oportunidad de seguir haciéndolo. En definitiva, una normativa que a pesar de sus limitaciones podrá ayudar a abordar el contexto de urgencia social que está produciendo debido a la irrupción de Airbnb, y en donde la sociedad civil y las instituciones menorquinas deberán actuar con celeridad y contundencia.

\section{Bibliografía}

ARIAS, A; QUAGLERI, A (2016). Unravelling Airbnb. Urban perspectives from Barcelona. En RUSSO, P, RICHARD, G (eds). Reinventing the local in Tourism. Bristol: Channel View, pp 209-225.

CASASNOVAS, M.A (2006). Història Econòmica de Menorca. La transformació d,una economia insular (1300-2000). Palma: Editorial Moll.

CÓCOLA GANT, A (2016). Holiday Rentals: The New Gentrification Battlefront. Sociological Research Online 21 (3) , [En línea] http://www.socresonline.org. uk/21/3/10.html [Consulta 16/03/2017]

CONSELL INSULAR DE MENORCA (2005). Pla Territorial Insular de Menorca [En línea] http://www.cime.es/WebEditor/Pagines/file/DOCPTI/PTI\%20Menorca\% 20 catala\%20PDF/02_Normes/00_Normes\%20catala.pdf [Consulta 21/08/2017]

CONSELL INSULAR DE MENORCA (2017). Registre d'habitatges turístics vacacionals. Base de datos no publicada.

CONSELLERIA DE TURISME (2015). Catàleg d'establiments turístics de les Illes Balears, 2015. Base de datos no publicada.

CORTÈS MARQUÈS, G (1990). Una Anàlisi de l'Oferta turística a Menorca. Maó, Institut Menorquí d'Estudis.

DIARI DE MENORCA (15/08/2016). Anuncios clasificados [En línea]. https://menorca. info/ [Consulta 1/2/2017].

DOMÈNEC, M et Al (1983). La Ciutat des del carrer : anàlisi formal, funcional i simbòlic del casc antic de Maó. Maó, Ateneu de Maó.

EXCELTUR y GOVERN DE LES ILLES BALEARS (2015). Estudio de Impacto económico del turismo sobre la economía y empleo de las Illes Balears [En línea]. www.caib.es/ sites/estadistiquesdelturisme/f/224873 [Consulta 21/08/2017]

GALÁN, R (12/04/2017). Cuando el alquiler turístico te soluciona la vida. Diario de Mallorca, [En línea] http://www.diariodemallorca.es/palma/2017/04/12/pisosingreso-extra/1206120.html [Consulta 07/03/2017]

GARCÍA, L.; SMITH, N. y MEJÍAS, M. Gentrification, displacement, and tourism in Santa Cruz de Tenerife. Urban Geography, 2007, Vol. 28, N³, p. 276-98.

GINARD, A (28/10/2016). Alquiler vacacional, un ingreso extraordinario. Diari de Menorca [En línea] https://menorca.info/balears/economico/2016/587900/ alquiler-vacacional-ingreso-extraordinario.html [Consula 4/7/2017]

GONZÁLEZ, J (04/12/2016). La escasez de pisos de alquiler dispara los precios hasta un $25 \%$ en un año. Diari de Menorca [En línea] https://menorca.info/menorca/ local/2016/590254/escasez-pisos-alquiler-dispara-precios-hasta-ano.html [Consula 4/7/2017] 
GOTHAM, K F. (2005). Tourism gentrification: The case of new Orleans' vieux carre (French Quarter). Urban studies, 42(7), 1099-1121.

GUTTENTAG, D. (2015). Airbnb: disruptive innovation and the rise of an informal tourism accommodation sector. Current issues in Tourism, 18(12), 1192-1217.

HIERNAUX, D e IMELDA GONZÁLEZ, X (2014). Turismo y gentrificación: pistas teóricas sobre una articulación. Revista de Geografía Norte Grande , 58:55-70.

INSIDEAIRBNB.COM (2017) How is Airbnb really being used in and affecting the neighbourhoods of your city? [En línea]. Disponible en http://insideairbnb.com/ [Consulta 16/04/2017].

INSTITUTO NACIONAL DE ESTADÍSTICA ( 1971 ). Censo de viviendas y población 1971. Madrid, Instituto Nacional de Estadística.

INSTITUTO NACIONAL DE ESTADÍSTICA (1991). Censo de viviendas y población 1991 [En línea]. http://www.ine.es/censo91/es/inicio.jsp [Consulta 7/4/2017].

INSTITUTO NACIONAL DE ESTADÍSTICA. Proyecto de los Censos Demográficos 2011. [En línea]. http://ine.es/censos2011_datos/cenl1_datos_inicio.htm [Consulta 8/4/2017].

LEES, L. (2003) Super-gentrification: the case of Brooklyn Heights, New York City, Urban Studies, 40(12), 2487 -2509.

LIN, J. (2008). Los Angeles Chinatown: Tourism, gentrification, and the rise of an ethnic growth machine. Amerasia Journal, 34(3), 110-125.

MARTIN, C.J (2016). The sharing economy: A pathway to sustainability or a nightmarish form of neoliberal capitalism?. Ecological Economics 121, 149-159.

MARTÍNEZ DE LA CRUZ, B; UTRILLA NAVARRO, L(1999). Aeropueto de Menorca. Medio siglo de Historia. Madrid: Aeropuertos Españoles y Navegación Aérea.

MORELL, M (2009). Fent barri: heritage tourism policy and neighbourhood scaling in Ciutat de Mallorca. Etnográfica, 13, (2), 343-372.

MULLINS, P. (1991). Tourism urbanization. International Journal of Urban and Regional Research, 15(3), 326-342.

MURRAY, I (2006) Menorca y sus ciudades. Otra rareza menorquina en las Baleares. En Artigues, A.A et al (eds). Introducción a la geografía urbana de las Illes Balears: VIII coloquio y jornadas de campo de Geografia Urbana, Illes Balears, 19-24 de junio de 2006, pp. 197-250.

MURRAY, I (2012). Geografies del capitalisme balear: poder, metabolisme socioeconòmic i petjada ecològica d'una superpotència turística. Tesis doctoral inédita, Universitat de les Illes Balears.

PAREJA EASTAWAY, M., \& SIMÓ I SOLSONA, M. (2014). Dinámicas en el entorno construido: renovación, gentrificación y turismo. El caso de la Barceloneta. ACE. Arquitecture, City and Environment-Arquitectura, Ciudad y Entorno, 2014, 9 (26), 201-222.

PONS, A; RULLAN SALAMANCA, O; MURRAY, I (2014) Tourism capitalism and island urbanization. tourist accomodation diffusion in the Balearics, 1936-2010. Island Studies Journal, 9 (2) 239-258. 
RIPOLL, A ( 1990). Els centres d'interès turístic nacional, el cas de Balears. Treballs de Geografia, 43, 71-82.

ROMERO, L. Y TRUDELLE, C. Mega-events and urban conflicts in Valencia, Spain: contesting the new urban modernity. Urban Studies Research, Vol. 2011 [En línea] [http://www.hindawi.com/journals/usr/2011/587523/ [Consulta 8/4/2017]

SMITH, N (1979). Toward a theory of gentrification a back to the city movement by capital, not people. Journal of the American Planning Association,45(4), 538-548.

SOLER, L (23/03/2017). “Para la temporada turística, hay pocos pisos de alquiler libres y además son muy caros". [En línea] http://cadenaser.com/emisora/2017/03/27/ radio_menorca/1490633186_502746.html [Consulta 09/04/2017]

TERRAFERIDA (28/03/2017). Desmuntant Airbnb. Part II [En línea]. https:// terraferida.cat/2017/03/28/desmuntant-airbnb-part-ii/

VICARIO, L.; MARTÍNEZ, M. Another 'Guggenheim effect'? The generation of a potentially gentrifiable neighbourhood in Bilbao. Urban Studies, 2003, 40 (12), 2383-2400.

VIVES, S. Producing a successful city. Neoliberal urbanism and gentrification in the tourist city. The case of Palma (Majorca). Urban Studies Research, Vol. 2011 [En línea]: http://www.hindawi.com/journals/usr/2011/989676/ [consulta 08/04/2017].

WYLY, E.; HAMMEL, D.J. (1998) Modeling the context and contingency of gentrification, Journal of Urban Affairs, 20(3), pp. 303-326

(C) Copyright: Ismael Yrigoy, 2017

(c) Copyright Scripta Nova, 2017.

Ficha bibliográfica:

YRIGOY, Ismael. Airbnb en Menorca: Una nueva gentrificación turística?: Localización de la vivienda turística, agentes e impactos sobre el alquiler residencial. Scripta Nova. Revista Electrónica de Geografía y Ciencias Sociales. [En línea]. Barcelona: Universidad de Barcelona, 15 de diciembre de 2017, vol. XXI, nº 580. ISSN: 1138-9788. 